\title{
Asynchronous Movements Prior to Pore Opening in NMDA Receptors
}

\author{
Rashek Kazi, ${ }^{1,2 \star}$ Quan Gan, ${ }^{1 \star}$ Iehab Talukder, ${ }^{1,2}$ Michael Markowitz, ${ }^{3}$ Catherine L. Salussolia, ${ }^{1,2}$ \\ and Lonnie P. Wollmuth ${ }^{3,4}$ \\ ${ }^{1}$ Graduate Program in Neuroscience, ${ }^{2}$ Medical Scientist Training Program (MSTP), ${ }^{3}$ Department of Neurobiology and Behavior, and ${ }^{4}$ Center for Nervous \\ System Disorders, Stony Brook University, Stony Brook, New York 11794-5230
}

Glutamate-gated ion channels embedded within the neuronal membrane are the primary mediators of fast excitatory synaptic transmission in the CNS. The ion channel of these glutamate receptors contains a pore-lining transmembrane M3 helix surrounded by peripheral M1 and M4 helices. In the NMDA receptor subtype, opening of the ion channel pore, mediated by displacement of the M3 helices away from the central pore axis, occurs in a highly concerted fashion, but the associated temporal movements of the peripheral helices are unknown. To address the gating dynamics of the peripheral helices, we constrained the relative movements of the linkers that connect these helices to the ligand-binding domain using engineered cross-links, either within (intra-GluN1 or GluN2A) or between subunits. Constraining the peripheral linkers in any manner dramatically curtailed channel opening, highlighting the requirement for rearrangements of these peripheral structural elements for efficient gating to occur. However, the magnitude of this gating effect depended on the specific subunit being constrained, with the most dramatic effects occurring when the constraint was between subunits. Based on kinetic and thermodynamic analysis, our results suggest an asynchrony in the displacement of the peripheral linkers during the conformational and energetic changes leading to pore opening. Initially there are large-scale rearrangements occurring between the four subunits. Subsequently, rearrangements occur within individual subunits, mainly GluN2A, leading up to or in concert with pore opening. Thus, the conformational changes induced by agonist binding in NMDA receptors converge asynchronously to permit pore opening.

\section{Introduction}

NMDA receptors are ligand-gated ion channels belonging to the ionotropic glutamate receptor (iGluR) family. They make essential and distinct contributions to excitatory transmission in the CNS and have been implicated in numerous brain diseases (Dingledine et al., 1999). A central determinant of NMDA receptor function is gating - the opening of the ion channel pore induced by agonist binding. NMDA receptors are obligate heterotetramers, typically composed of two glycine-binding GluN1 and two glutamate-binding GluN2 subunits (Traynelis et al., 2010). Opening of the NMDA receptor ion channel requires all four agonist binding sites to be occupied (Kleckner and Dingledine, 1988) and occurs largely simultaneously across the subunits (Schorge et al., 2005; Kussius and Popescu, 2009).

In iGluR subunits, the extracellular ligand-binding domain (LBD) is comprised of two discontinuous polypeptides ( $\mathrm{S} 1$ and

Received Dec. 18, 2012; revised May 2, 2013; accepted June 14, 2013.

Author contributions: R.K., Q.G., I.T., and L.P.W. designed research; R.K., Q.G., I.T., M.M., and C.L.S. performed research; R.K., Q.G., I.T., M.M., and C.L.S. analyzed data; R.K., Q.G., and L.P.W. wrote the paper.

This work was supported by a NIH R01 Grant from NIMH (MH066892; L.P.W.), a NRSA NIH Predoctoral Fellowship from NINDS (NS077541; R.K.), and an American Heart Association Predoctoral Fellowship (I.T.). We thank Janet Allopenna for technical assistance and Dr. Jie Yang and Jiansong Chen from The Stony Brook University Medical Center Biostatistics Core for assisstance with statistical analyses and interpretation.

*R.K. and Q.G. contributed equally to this work.

Correspondence should be addressed to Dr. Lonnie P. Wollmuth, Department of Neurobiology and Behavior, Center for Nervous System Disorders, State University of New York at Stony Brook, Stony Brook, New York 117945230. E-mail: Ionnie.wollmuth@stonybrook.edu.

DOI:10.1523/JNEUROSCI.5780-12.2013

Copyright $\odot 2013$ the authors $\quad 0270-6474 / 13 / 3312052-15 \$ 15.00 / 0$
S2) (Armstrong and Gouaux, 2000; Furukawa et al., 2005; Mayer, 2006). The transmembrane domain (TMD), which forms the ion channel, is composed of three transmembrane helices (M1, M3, and M4) and a reentrant pore-loop (M2) (Sobolevsky et al., 2009). In iGluRs, opening of the ion channel entails shifting of the major pore-lining M3 helices away from the central axis of the pore (Fig. 1) (Jones et al., 2002; Sobolevsky et al., 2002, 2009; Chang and Kuo, 2008), presumably driven by the M3-S2 linkers, the short polypeptide linkers that connect the M3 helices to the LBD (Sun et al., 2002; Hansen et al., 2007). In the GluA2 structure, where the ion channel is closed, the centrally located M3 helices and M3-S2 linkers are surrounded by the M1 and M4 helices and the linkers, S1-M1 and S2-M4, that connect them to the LBD (Fig. 1) (Sobolevsky et al., 2009). Functional experiments have shown that these peripheral structural elements can modulate gating (Krupp et al., 1998; Balannik et al., 2005; Schmid et al., 2007; Talukder et al., 2010; Ren et al., 2012). Given the tight physical association between the peripheral helices and linkers and the central gating structures, these peripheral elements presumably must reposition for efficient channel gating to occur (Sobolevsky et al., 2009). This idea remains untested. Further, the temporal relationship between the dynamics of these peripheral elements and pore opening remains unknown.

To address the dynamics of these peripheral structural elements in NMDA receptors, we constrained the relative movement of the S1-M1 and S2-M4 linkers, either in an intra- (within GluN1 or GluN2A) or inter- (between GluN1 and GluN2A) subunit fashion using disulfide cross-links. For either intra- or 


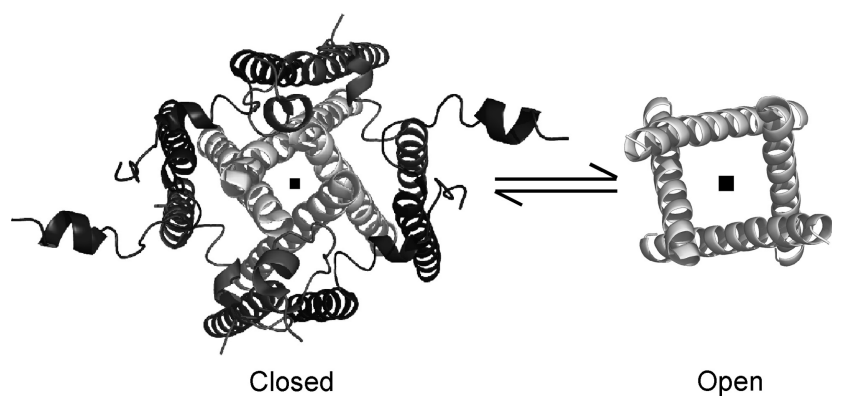

Figure 1. Pore opening in iGluRs involves displacement of the $M 3$ transmembrane helix. Left, A top-down view of the transmembrane domain (helices M1, M3, and M4) in the antagonist-bound (channel pore closed) GluA2 structure (PDB ID 3KG2) (Sobolevsky et al., 2009). The M3 helices (light gray) directly line the ion channel pore (square indicates central axis of the pore), while the M1 and M4 helices along with their associated linkers (dark gray) are located peripherally. Right, In an open-channel structure of Shaker Kv1.2 (2A79) (Long et al., 2005), the M3 helices [homologous to TM2 or S6 in $\mathrm{K}^{+}$channels (Wo and Oswald, 1995)] are splayed out compared with the close state. For iGluRs, the positioning of the peripheral structural elements as well as the specific details for the M3 helices in the open state are unknown.

inter-subunit constraints, gating was significantly impaired, highlighting the requirement for a rearrangement of these peripheral structural elements for efficient gating to occur. Surprisingly, however, we also found that the relative movements between different pairs of peripheral linkers are not temporally equivalent, indicating an asynchrony in the sequence of events from agonist binding to pore opening. Hence, although the overall gating process is largely concerted across the four subunits, elementary events occur in a stepwise fashion. Targeting these events may represent a means to modulate NMDA receptors clinically.

\section{Materials and Methods}

Mutagenesis and expression. Cysteine substitutions in rat GluN1a (NCBI Protein database accession no. P35439) and GluN2A (accession no. Q00959) subunits were generated using QuikChangeSite-Directed $\mathrm{Mu}-$ tagenesis Kit (Stratagene.) (Yelshansky et al., 2004). Xenopus laevis oocytes were prepared, coinjected with cRNA encoding GluN1a and GluN2A, and maintained as previously described (Sobolevsky et al., 2002). Macroscopic current recordings were made 3-4 d after the injection. For mammalian cell expression, human embryonic kidney (HEK) 293 cells were cotransfected with cDNA encoding GluN1 and GluN2A, as well as a vector for enhanced green fluorescent protein (pEGFP-Cl; Clonetech) at a ratio of 1:1:1 using Fugene 6 (Roche). Single-channel recordings were made $24-48 \mathrm{~h}$ following transfection.

Macroscopic current recordings and analysis. Macroscopic currents from Xenopus oocytes were recorded using two-electrode voltage clamp (TEVC-200A; Dagan Corporation) with Cell Works software (NPI Electronic) at room temperature $\left(20-23^{\circ} \mathrm{C}\right)$. Microelectrodes were filled with $3 \mathrm{M} \mathrm{KCl}$ and had resistances of 1-4 M $\Omega$. The external solution ("Bath Solution") consisted of the following (in mM): $115 \mathrm{NaCl}, 2.5 \mathrm{KCl}$, $0.18 \mathrm{BaCl}_{2}, 5$ HEPES, and $100 \mu \mathrm{M}$ EDTA (pH 7.2, NaOH). All reagents including glycine $(20 \mu \mathrm{M})$ and glutamate $(200 \mu \mathrm{M})$, competitive antagonists 5,7-dichlorokynurenic acid (DCKA, $10 \mu \mathrm{M}$ ) and DL-2-amino-5phosphonopentanoic acid (APV, $100 \mu \mathrm{M})$, as well as the reducing agent dithiothreitol (DTT, $4 \mathrm{~mm}$ ) were applied with the bath solution. All reagents were obtained from Roche or Sigma-Aldrich.

To assay the effects of DTT on macroscopic currents in oocytes, we calculated the percentage potentiation ( $\%$ potentiation) in agonistactivated current amplitude $\left(I_{\text {post }}-I_{\text {pre }}\right) / I_{\text {pre }} \times 100$, measured before $\left(I_{\text {pre }}\right)$ and either during or after $\left(I_{\text {post }}\right)$ a DTT application. $I_{\text {pre }}$ and $I_{\text {post }}$ were averages of amplitudes of currents elicited by three to five $15 \mathrm{~s}$ applications of glutamate and glycine separated by $45-60 \mathrm{~s}$ washes in agonist-free solution. Corrections for current run-down over time were calculated by fitting a single-exponential curve to at least three pre-DTT agonist-activated current amplitudes. All analysis was performed using Igor Pro (WaveMetrics) with in-laboratory written programs as previously published (Sobolevsky et al., 2002; Talukder et al., 2010).

DTT was applied in one of two ways. For screening proximal positions using pairs of introduced cysteines, we applied DTT continuously for $\sim 5$ min while measuring $I_{\text {post }}$. The advantage of this protocol is the lack of possible bias due to state-dependent action of DTT since receptors visited both the open and closed states when exposed to DTT. Alternatively, for experiments to assay properties of DTT-induced current potentiation, we applied DTT for $120 \mathrm{~s}$ in an agonist-free solution containing competitive antagonists DCKA and APV, and measured $I_{\text {post }}$ after removal of DTT and antagonists. This latter protocol greatly improved oocyte health (as evidenced by reduced changes in the baseline current amplitude and increased survivability during recordings).

Protein chemistry. Whole-cell membrane proteins were isolated as described previously (Salussolia et al., 2011b). Briefly, 10-12 healthy oocytes expressing wild-type GluN1/GluN2A receptors or cysteinesubstituted subunits were fixed in PBS containing $58 \mathrm{~mm}$ $N$-ethylmaleimide (NEM, Pierce), lysed (20 mM Tris, $0.58 \mathrm{~mm}$ NEM), and centrifuged. The supernatant was recovered and ultracentrifuged at 40,000 RPM (Beckman TLA 120.2 rotor) for $10 \mathrm{~min}$. The pellet was resuspended in PBS and ultracentrifuged again at 40,000 RPM. The resultant pellet was resuspended in solubilization buffer [ $20 \mathrm{~mm}$ Tris, 50 $\mathrm{mm} \mathrm{NaCl}, 1 / 1000$ protease inhibitor mixture (Sigma), and $0.58 \mathrm{~mm}$ $\mathrm{NEM}$ ] without detergent and then incubated with detergents $(0.03 \%$ Na-deoxycholate, $1 \%$ Triton $\mathrm{X}-100)$ at $4^{\circ} \mathrm{C}$ for $1 \mathrm{~h}$. Solubilized proteins were ultracentrifuged for $20 \mathrm{~min}$ at 40,000 RPM, and membrane proteins contained in the supernatant were separated by SDS-PAGE under nonreducing or reducing (100 mM DTT) conditions.

Proteins were transferred from the gel to $0.45 \mathrm{~mm}$ nitrocellulose membranes by semidry transfer (Bio-Rad) using Bjerrum-Schaffer-Nielsen buffer. Blots were blocked and incubated with either mouse anti-GluN1 (1:500; Millipore MAB363) or rabbit anti-GluN2A (1:300; Millipore $\mathrm{AB} 1555 \mathrm{P})$ overnight at $4^{\circ} \mathrm{C}$. Blots were washed before incubation with HRP-conjugated goat anti-mouse (sc-2302) or HRP-conjugated goat anti-rabbit (sc-2030) and developed with Western Blot Luminol Reagent (sc-2048, all Santa Cruz Biotechnology reagents) and exposed to chemiluminescence film (Crystalgen, Blue Sensitive Film, CGFB-507).

Single-channel recordings and analysis. All single-channel recordings were performed in the "on-cell" configuration at steady state using transfected HEK 293 cells. The pipette solution used (mimicking extracellular agonist conditions) contained the following (in $\mathrm{mm}$ ): $150 \mathrm{NaCl}, 10$ HEPES, 1 EDTA, 1 glutamate, and 0.1 glycine, $\mathrm{pH} 8.0(\mathrm{NaOH})$. The high $\mathrm{pH}$ and EDTA were used to minimize proton and divalent mediated inhibitory effects, respectively (Popescu and Auerbach, 2003; Kussius and Popescu, 2009; Talukder et al., 2011). Recording pipettes were pulled from thick-wall borosilicate capillary glass (Sutter Instruments) and firepolished to final pipette resistances ranging from 5-50 M $\Omega$ when measured in the bath solution (with an applied positive pipette pressure of $\sim 200$ mbar). Cells were identified by GFP fluorescence and patched to resistances exceeding $1.5 \mathrm{G} \Omega$. To elicit distinct inward current amplitudes, we held the electrode voltage at $+100 \mathrm{mV}$. Currents were recorded using a patch-clamp amplifier (Axopatch 200B; Molecular Devices), filtered at $10 \mathrm{kHz}$ (four-pole Bessel filter), and digitized at $40 \mathrm{kHz}$ (ITC-16 interfaced with PatchMaster). Experiments ran for $\sim 15-20$ min to ensure a significant number of events for analysis. To assay the effects of DTT on single-channel activity, we applied $4 \mathrm{~mm}$ DTT in both the bath (before forming the gigaseal) and pipette solutions (Talukder et al., 2011).

Analysis of single-channel records was comparable to that by Talukder and Wollmuth (2011). Briefly, after recordings were complete, data were exported from PatchMaster to QuB (http://www.qub.buffalo.edu) for analysis. Recordings of GluN1/GluN2A receptors without DTT and all receptors with DTT consisted of long clusters of activity separated by seconds-long periods of inactivity, simplifying detection of several channels in the patch. For these recordings, the relatively high open probability $\left(P_{\mathrm{o}}\right)$ and duration of recordings ( $\sim 90,000-1,000,000$ events) indicated that we were recording from single-channel patches. 
For several cross-linked constructs, the $P_{\mathrm{o}}$ without DTT was extremely low, which made single-channel patches detection difficult. First, many patches were recorded but excluded during analysis because of obvious simultaneous openings of multiple channels. Of the remaining patches, only minutes-long recordings (with 13,000-100,000 events) without any apparent simultaneous openings were further analyzed. Of the singlechannel $P_{\mathrm{o}}$ values tabulated, the lowest was 0.002 for GluN1(F540C)/ GluN2A(S791C). If the patch contained two active channels of equivalent open probability, then a double-channel opening would be expected approximately once every 500 events (Colquhoun and Hawkes, 1990; Dravid et al., 2008). On average, enough events were recorded to be $\sim 99 \%$ confident that activity was from a single channel (analysis not shown). For GluN1(F540C)/GluN2A(S791C), two patches contained too few events to be completely confident that there was only a single channel but these two records had open probabilities less than the average $P_{\mathrm{o}}$ observed for this receptor. Hence, we assume that there was not more than one channel in these patches.

Processed data were idealized using the segmental k-means (SKM) algorithm. Kinetic analysis was performed using the maximum interval likelihood (MIL) algorithm in QuB with a dead time of $150 \mu$ s. Kinetic models of NMDA receptor gating activation have been proposed to contain $\sim 5$ closed states and more than one open state (Banke and Traynelis, 2003; Popescu and Auerbach, 2003; Auerbach and Zhou, 2005; Schorge et al., 2005; Erreger and Traynelis, 2008). We used a linear, fully liganded state model containing 3 closed states, 2 desensitized states, and 2-4 open states (Auerbach and Zhou, 2005; Kussius and Popescu, 2009).

In the present study, we investigated five receptor types, wild-type and 4 receptors containing double cysteine-substitutions, using single channel analysis. Each receptor was studied either in the absence or presence of DTT. For each individual record, state models with increasing closed (3-6) and open (2-4) states were constructed and fitted to the recordings until log-likelihood (LL) values improved by $<10 \mathrm{LL}$ units/added state or if the next added state showed $0 \%$ occupancy (Kussius and Popescu, 2009; Talukder and Wollmuth, 2011). For closed-time distribution, all receptors except for one [GluN1(S531C-F792C)/GluN2A] was best fit by five closed states. For GluN1(S531C-F792C)/GluN2A in the absence of DTT, four of five recordings were best fit by six closed states, but the sixth component displayed an occupancy of $<0.01 \%$, suggesting that it was a minor component of gating.

The open-time components, comprising one common short duration $\left(\mathrm{O}_{1}\right)$ and up to three long duration $\left(\mathrm{O}_{2}-\mathrm{O}_{4}\right)$ intervals arise from modal gating of NMDA receptors (Kussius and Popescu, 2009). For each individual record, we initially fit open time distributions with 2-4 open states. In the presence of DTT, the open time distributions were best fit by four open states for all receptors studied. In the absence of DTT, where the probability of being open was extremely low for certain cysteinesubstituted receptors, some individual records were best fit by only two or three open states, although for each receptor there were examples of best fits with four open states (typically those with very long recording times where many events were present). As such, we could not confidently perform statistical analysis regarding modal gating (four open states). We therefore fit all open-time distributions with only two open components, a short-duration open state $\left(\mathrm{O}_{1}\right)$ and a single "longduration" open state $\left(\mathrm{O}_{2}\right)$ (Kussius and Popescu, 2009; Kussius et al., 2010; Borschel et al., 2011; Talukder and Wollmuth, 2011). Time constants and the relative areas of each component, the transition rate constants, as well as mean closed time (MCT) and mean open time (MOT) were averaged for each receptor without and with DTT and compared with each other.

Thermodynamic effect of constraining linker mobility. We quantified the Gibbs free energy of each transition using the following:

$$
\Delta G=-R T \ln \left(\frac{K_{\mathrm{f}}}{K_{\mathrm{r}}}\right),
$$

where $K_{\mathrm{f}}$ and $K_{\mathrm{r}}$ refer to the forward and reverse rates of that transition, $R$ is the empirical gas constant $\left(1.987 \times 10^{-3} \mathrm{kcal} / \mathrm{mol}\right)$, and $T$ is the recording temperature (295 Kelvin). To assay the thermodynamic effect of constraining linker mobility via cross-linking, we quantified differ- ences in energy for each kinetic transition between the DTT $\left(\Delta G_{+ \text {DTT }}\right)$ and non-DTT ( $\left.\Delta G_{\text {-DTT }}\right)$ conditions, as follows:

$$
\Delta \Delta G=\Delta G_{+ \text {DTT }}-\Delta G_{- \text {DTT }} .
$$

Statistics. Data analysis and statistics was performed using IgorPro (WaveMetrics), QuB, Excel (Microsoft), and SAS 9.3 (SAS). Whole-cell and single-channel current amplitudes and single-channel properties are presented as mean \pm SEM. We used a two-tailed Student's $t$ test to test whether the degree of DTT-induced potentiation was greater than that for wild-type (for macroscopic currents) and to test significant differences between single-channel properties for cysteine-substituted receptors and wild-type under the various conditions $(+/-D T T)$. Student's $t$ test was also used to test for a significant difference in $\Delta G$ values between + DTT and - DTT conditions for GluN1/GluN2A. Statistical significance was set at $p<0.05$.

Statistical differences for thermodynamic effects of cross-linking were defined as follows (Stony Brook Biostatistics Core Facility): A three-way ANOVA model was used to model experimental data with receptor, kinetic transition, and DTT condition. Their two- and three-way interactions were also included in the model. Normality assumption was confirmed. This model allows us to test different linear contrasts and $t$ test was used to test whether any linear contrast is statistically different from 0 . The hypothesis being tested in this study is whether the $\Delta \Delta G$ value differs between two different kinetic transitions for a specific construct (e.g., between the $\mathrm{C} 3-\mathrm{C} 2$ transition and the $\mathrm{C} 2-\mathrm{C} 1$ transition of GluN1(S531C-F792C)/GluN2A) or between two different constructs for a specific kinetic transition [e.g., between GluN1(S531C-F792C)/ GluN2A and GluN1/GluN2A for the C3-C2 transition]. Because we were interested in the significance level of each hypothesis (comparison), we did not use a multiple-comparison adjustment. Statistical significance was set at $p<0.05$ and performed using SAS 9.3.

\section{Results}

To study the dynamics of the peripheral linkers, S1-M1 and S2-M4, during NMDA receptor gating, we constrained their mobility using spontaneously formed disulfide bonds between pairs of introduced cysteines. Initially, we designed experiments to identify intra- and inter-subunit pairs of positions between S1-M1 and S2-M4 that form disulfide bonds when substituted with cysteine.

\section{Identification of intra- and inter-subunit cross-linking between S1-M1 and S2-M4 linkers in NMDA receptor subunits}

To identify intra-subunit proximal pairs between S1-M1 and S2-M4, we chose S531 in the S1-M1 of GluN1 (Fig. 2A) and V525 in the S1-M1 of GluN2A (Fig. 2B) as reference points (Talukder et al., 2010) and screened multiple positions for potential crosslinking partners in the S2-M4 linker of the same subunit (T789 to M795 in GluN1, Fig. 2A and Q792 to M798 in GluN2A, Fig. 2B). Proximal positions to the reference points were selected based on homologous residues in the AMPA receptor GluA2 structure (Sobolevsky et al., 2009). Nevertheless, using the LBD-TMD linkers of AMPA receptors as a model for those in NMDA receptor subunits has limitations since they differ in length (note dashes in alignments in Figs. 2A, B) (Sobolevsky et al., 2009; Talukder et al., 2010; Traynelis et al., 2010).

For the reference point GluN1(S531), only GluN1(S531CF792C)/GluN2A showed a significantly greater potentiation of agonist-activated current amplitudes during DTT exposure $(660 \pm 360 \%, n=8$, mean \pm SEM, number of recordings) than wild-type GluN1/GluN2A ( $27 \pm 4 \%, n=11$ ) (Fig. $2 C, E)$. For the reference point GluN2A(V525), receptors containing cysteine substitutions at three S2-M4 positions (Q792, D794 or D796) showed significantly greater DTT-induced current potentiation 

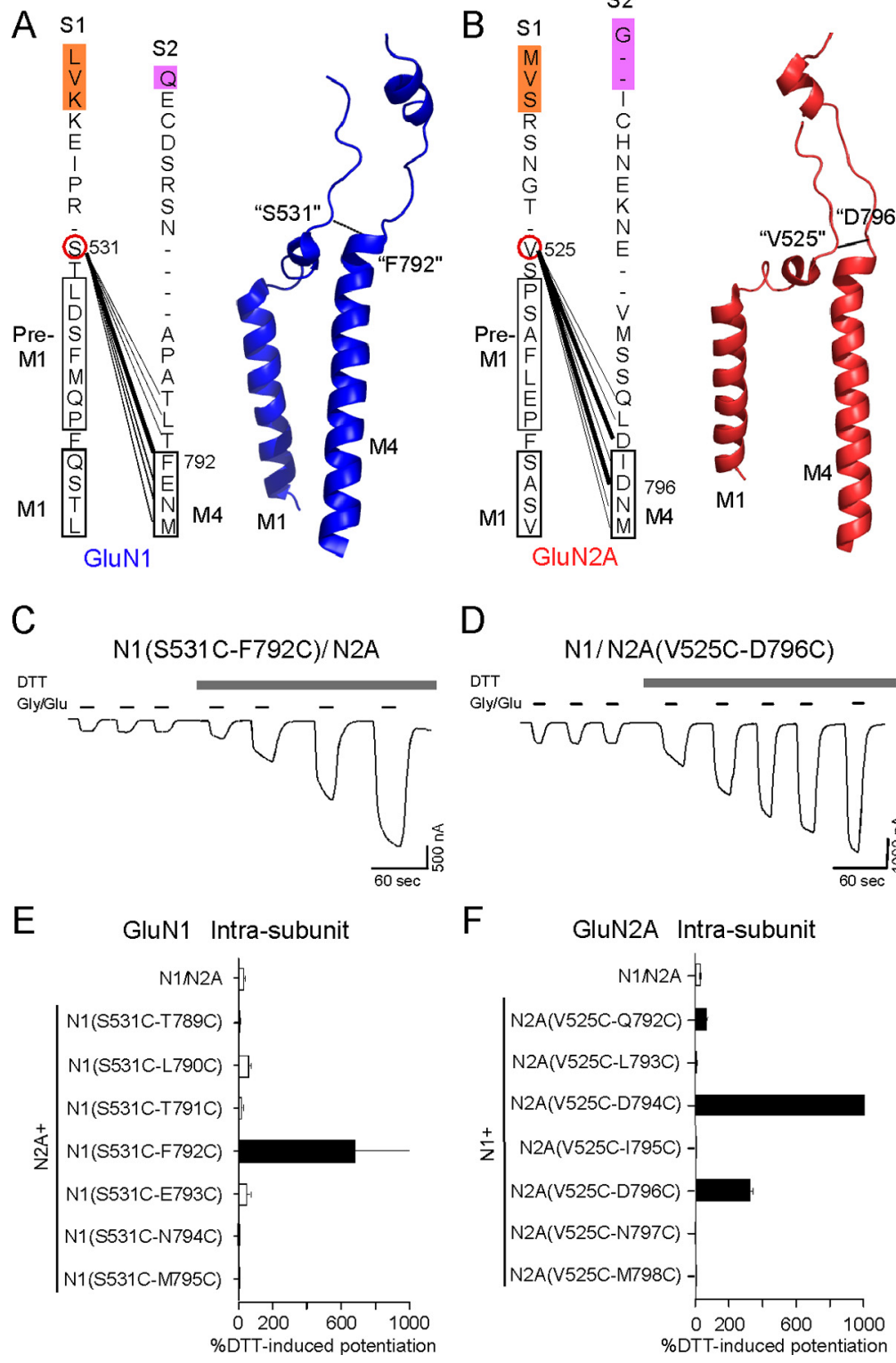

Figure 2. Intra-subunit cross-linking between S1-M1 and S2-M4 linkers of NMDA receptor subunits. $A, B$, Left, Sequences of the S1-M1 and S2-M4 linkers of GluN1 $(A)$ and GluN2A $(B)$ with boxes indicating regions assumed to be helical based on sequence alignment with GluA2. Short dashes in the sequences indicate gaps in the alignment. Right, Structures of these linkers along with the transmembrane segments they are connected to in GluA2 (Sobolevsky et al., 2009). Subunits in the $\boldsymbol{A} / \boldsymbol{C}$ (approximating GluN1) and in the $\boldsymbol{B} / \boldsymbol{D}$ (approximating GluN2A) conformation (Salussolia et al., 2011a) are colored blue and red, respectively. The S1-M1 positions GluN1(S531) and GluN2A(V525) (red circles) were chosen as reference points. Multiple cysteine substitutions in the S2-M4 linker of the same subunit were screened in combination with S531C or V525C. Pairs of substitutions showed either no difference (thin lines) or significantly greater DTT-induced current potentiation (thick lines) compared with wild-type when exposed to DTT. GluN1(S531C-F792C) and GluN2A(V525C-D796C), whose homologous residues in GluA2 are shown in the structure, were selected as "focal pairs" of cysteine substituted receptors for subsequent experiments. C, D, Representative membrane currents (holding potential $V_{\mathrm{h}}=-60 \mathrm{mV}$ ) in Xenopus oocytes injected with GluN1(S531C-F792C)/GluN2A (C) or GluN1/ GluN2A(V525C-D796C) (D). Currents were elicited by coapplication of $20 \mu \mathrm{m}$ glycine and $200 \mu \mathrm{m}$ glutamate (black lines). Agonistactivated current amplitudes were potentiated when $4 \mathrm{~mm}$ DTT (gray bar) was applied. $\boldsymbol{E}, \boldsymbol{F}$, Mean percentage potentiation of current amplitudes ( $\pm \mathrm{SEM} ; \mathrm{n} \geq 3$ ) during DTT exposure. Solid bars represent cysteine-substituted receptors showing significantly greater potentiation ( $p<0.05$, Student's $t$ test) than wild-type GluN1/GluN2A $(27 \pm 4.0 \%, n=11)$. For GluN1(S531CF792C) $(\boldsymbol{E})$, the error bar is not fully shown, whereas for GluN1/GluN2A(V525C-D794C) the mean value is not fully shown $(390,000 \pm 150,000 \%)$.

$(63 \pm 6.7 \%, n=4 ; 390,000 \pm 150,000 \%, n=4 ; 320 \pm 16 \%, n=$ 4 ; respectively) than wild-type (Fig. $2 D, F$ ).

To identify inter-subunit proximal pairs, we used S791 in S2-M4 of GluN2A and P787 in S2-M4 of GluN1 as reference points and screened for proximal positions in the S1-M1 of the opposite sub- unit (M537 to T543 in GluN1, Fig. $3 A$ and F534 to S537 in GluN2A, Fig. 3B, respectively). For the reference point GluN2A(S791), the only pair of cysteines showing a significantly greater DTT-induced current potentiation than wild-type was GluN1(F540C)/ GluN2A(S791C) $(290 \pm 6 \%, n=3)$ (Fig. 3C,E). For the reference point GluN1(P787), receptors containing cysteine substitutions at three positions in the S1-M1 of GluN2A (F534, S535 and A536) showed significantly greater DTT-induced current potentiation $(440 \pm 47 \%, n=4$; $730 \pm 190 \%, n=4 ; 21,000 \pm 1500 \%, n=4$; respectively) than wild-type (Fig. $3 D, F$ ).

\section{DTT-induced current potentiation is due to breakage of a disulfide bond between introduced cysteines}

For subsequent experiments, we focused on four pairs of positions ("focal pairs"): two intra-subunit, GluN1(S531C-F792C) and GluN2A(V525C-D796C) and two intersubunit, GluN1(P787C)/GluN2A(S535C) and GluN1(F540C)/GluN2A(S791C). In some instances, to refer to the focal pairs and to emphasize the location of the cross-linked pairs, we used abbreviations with the number indicating the most proximally connected transmembrane segment (1 for M1, 4 for M4): GluN1(1C-4C) for GluN1(S531C-F792C); GluN2A(1C-4C) for GluN2A(V525C-D796C); GluN1(1C)/ GluN2A(4C) for GluN1(F540C)/GluN2A(S791C); and GluN1(4C)/GluN2A(1C) for GluN1(P787C)/GluN2A(S535C) (Fig. 4A). For these more focused experiments using macroscopic currents, we applied DTT for $120 \mathrm{~s}$ in the presence of competitive antagonists (DCKA and APV; see Materials and Methods).

As illustrated in Figure 4, $B$ and $C$, DTT, when applied in the presence of competitive antagonists, significantly potentiated current amplitudes for GluN1(1C-4C)/ GluN2A (640 $\pm 190 \%, n=6)$, GluN1/ GluN2A(1C-4C) (350 $\pm 34 \%, n=6)$, GluN1(1C)/GluN2A(4C) (110 $\pm 4 \%, n=$ 6), and GluN1(4C)/GluN2A(1C) (360 \pm $49 \%, n=5)$ when compared with wild-type $(6 \pm 7 \%, n=5)$. In contrast, none of the receptors with only a single cysteine substitution showed significant DTT-induced current potentiation (Fig. 4B,C). These results are consistent with the idea that the DTT-induced current potentiation arises from breakage of cross-links between pairs of introduced cysteines in two different subunits rather than in two subunits of the same type (e.g., between S531C in two GluN1 subunits) or between introduced and endogenous cysteines (Fig. 4A).

To further test the idea that DTT-induced current potentiation reflects breakage of introduced disulfide bonds, we used immunoblots to 
analyze the focal pairs under either nonreducing (Fig. 4D) or reducing (Fig. 4E) conditions. Consistent with inter-subunit crosslinking, both GluN1(4C)/GluN2A(1C) and GluN1(1C)/GluN2A(4C) showed dimer bands when probed with either anti-GluN1 (Fig. 4D, left) or anti-GluN2A (Fig. 4D, right) antibodies. These heterodimers bands were absent under reducing conditions (Fig. 4E). On the other hand, GluN1(1C-4C)/ GluN2A and GluN1/GluN2A(1C-4C) only showed monomer bands under nonreducing conditions, consistent with cross-linking occurring within an individual subunit rather than between like subunits.

Cross-links could have arisen during biogenesis but may not occur in the intact, functional receptor. Therefore, we tested the rate of spontaneous reformation of broken disulfide bonds using the decrease in whole-cell current amplitudes after removing DTT from the bath solution as an index of bond reformation (data not shown). For the four focal pairs, current amplitudes decreased after removing DTT with a time constant varying between 200 and $400 \mathrm{~s}$ depending on the constructs. Hence, the disulfide bonds broken by DTT spontaneously reform in intact, functional receptors, suggesting that the receptor conformation(s) in which the introduced cysteines cross-link are visited in a surfaceexpressed functional receptor.

To quantify the effects of cross-linking on gating, we used single channel recordings in HEK 293 cells as presented in subsequent sections. For these recordings, we used a solution that was at $\mathrm{pH} 8.0$ and contained EDTA (1 mM) (see Materials and Methods). In contrast, the oocyte solution was at $\mathrm{pH} 7.2$, contained a small amount of $\mathrm{Ca}^{2+}(0.18 \mathrm{~mm})$ and did not contain EDTA. These factors, $\mathrm{pH}$ and divalent composition, can have significant effects on NMDA receptor gating (Traynelis et al., 2010). Hence, we did not study the quantitative differences within the oocyte results nor did we compare these results to those in HEK 293 cells. Rather, we used the oocyte results only as a screen to identify cross-linking pairs of positions that would be further studied at the single channel level.

\section{Constraining the peripheral linkers impedes NMDA receptor opening}

To address the dynamics of the peripheral linkers during NMDA receptor gating, we measured single-channel activity for wildtype receptors and the receptors with focal pairs of introduced cysteines (Fig. 4A). Figure 5 illustrates single-channel activity for wild-type $(A)$, as well as intra- $(B, C)$ or inter- $(D, E)$ subunit focal pairs. All recordings were from patches containing exactly one channel measured in the on-cell configuration and were re-
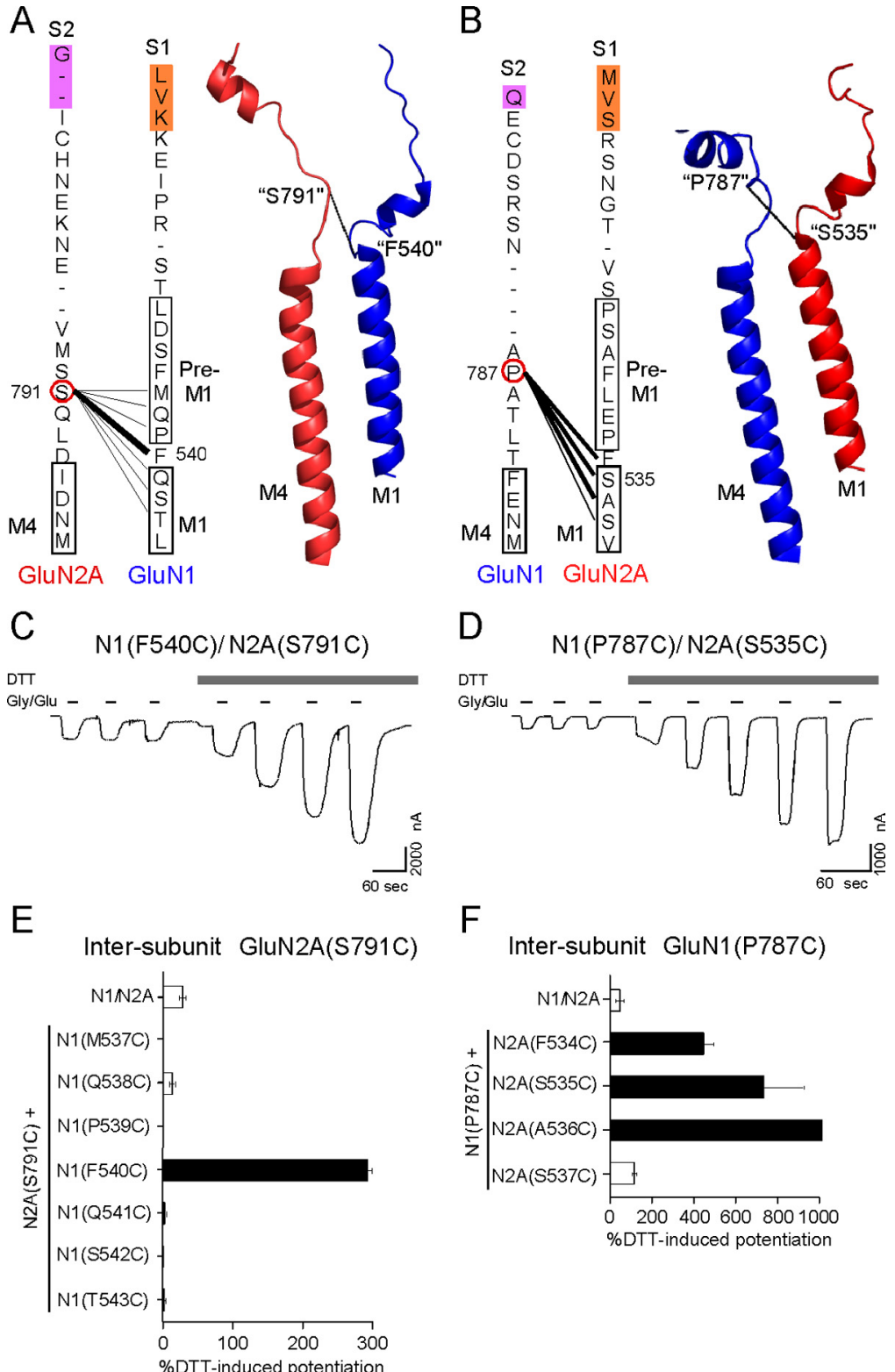

F

Inter-subunit GluN1(P787C)

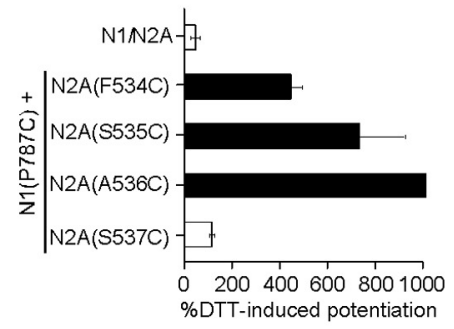

Figure 3. Inter-subunit cross-linking between S1-M1 and S2-M4 linkers of NMDA receptor subunits. $A, B$, The sequences of the S1-M1 and S2-M4 linkers of GluN1 and GluN2A as well as related structural elements in the GluA2 crystal structure are shown as in Figure 2, but paired in an inter-subunit manner. The S2-M4 positions GluN2A(S791) and GluN1(P787) (red circles) were chosen as reference points for screening introduced cysteines in the S1-M1 linkers of the other subunits. GluN1(F540C)/ (5791C) and GluN1(P787C)/GluN2A(S535C) whose homologous residues are shown in the structure, were selected as focal pairs of cysteine substituted receptors used for further studies. C, D, Membrane currents in oocytes injected with GluN1(F540C)/ GluN2A(S791C) (C) or GluN1(P787C)/GluN2A(S535C) (D) and displayed as in Figure 2, Cand D. E, F, Mean percentage potentiation of current amplitudes ( \pm SEM; $n \geq 3$ ) during DTT exposure are displayed as in Figure $2, E$ and $F$. The potentiation for GluN1(P787C)/GluN2A(A536C) (F) $(21,000 \pm 1500 \%, n=4)$ is not fully displayed.

corded in either the absence ( - DTT; left) or presence (+DTT; right) of DTT (see Materials and Methods). In the absence of DTT (Fig. 5, left), the intra- and inter-subunit cross-linked receptors showed dramatic reductions in single-channel activity compared with wild-type while maintaining its general gating properties (burst activity, multiple closed and open times, and a single conductance level; see Materials and Methods). Under reducing conditions (Fig. 5, right), all constructs, including wildtype, showed significant increases in channel activity, albeit to varying degrees. 
A

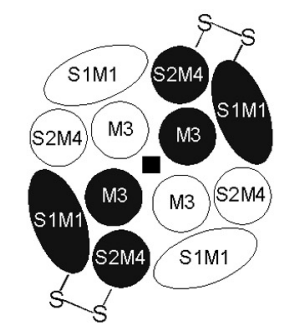

N1(S531C-F792C)/N2A

or

$\mathrm{N} 1(1 \mathrm{C}-4 \mathrm{C}) / \mathrm{N} 2 \mathrm{~A}$

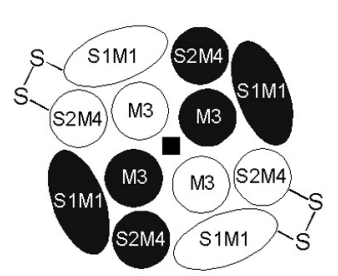

N1/N2A(V525C-D796C)

or

$\mathrm{N} 1 / \mathrm{N} 2 \mathrm{~A}(1 \mathrm{C}-4 \mathrm{C})$

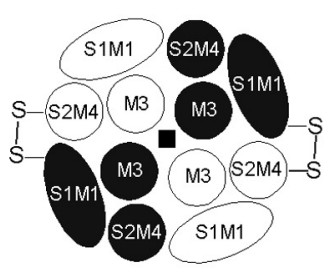

$\mathrm{N} 1(\mathrm{~F} 540 \mathrm{C}) / \mathrm{N} 2 \mathrm{~A}(\mathrm{~S} 791 \mathrm{C})$
or

$\mathrm{N} 1(1 \mathrm{C}) / \mathrm{N} 2 \mathrm{~A}(4 \mathrm{C})$

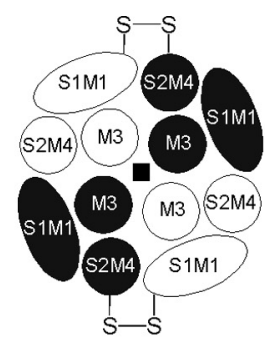

N1(P787C)/N2A(S535C)

or

$\mathrm{N} 1(4 \mathrm{C}) / \mathrm{N} 2 \mathrm{~A}(1 \mathrm{C})$
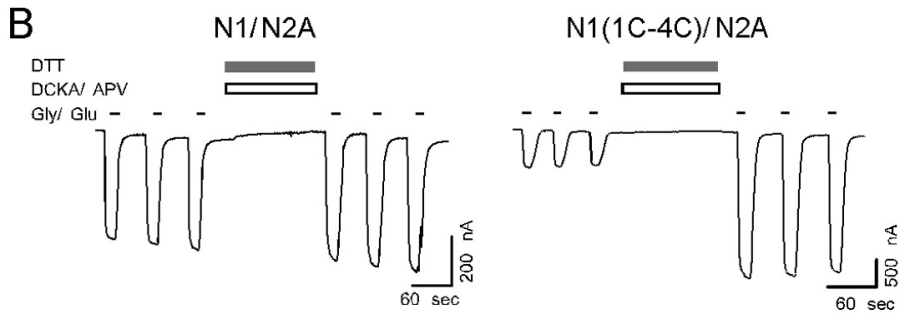

$\mathrm{N} 1(1 \mathrm{C}) / \mathrm{N} 2 \mathrm{~A}$

$\mathrm{N} 1(4 \mathrm{C}) / \mathrm{N} 2 \mathrm{~A}$

C
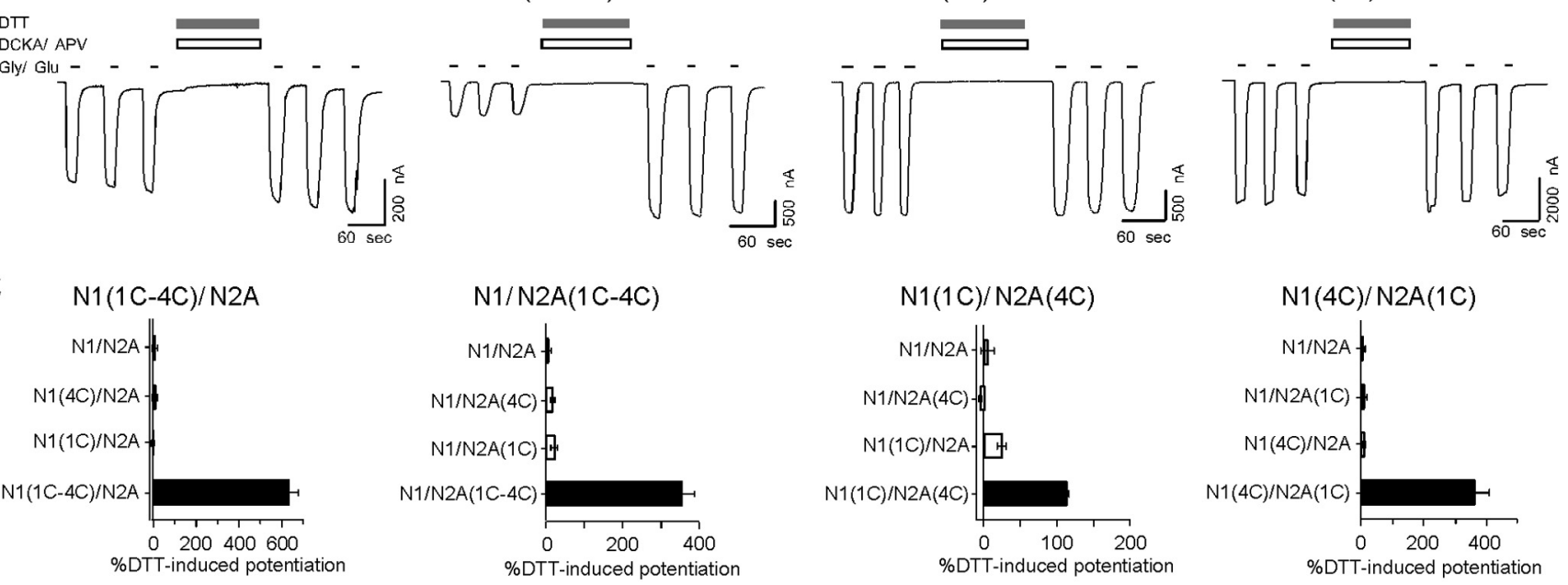

D

Non-reducing

E
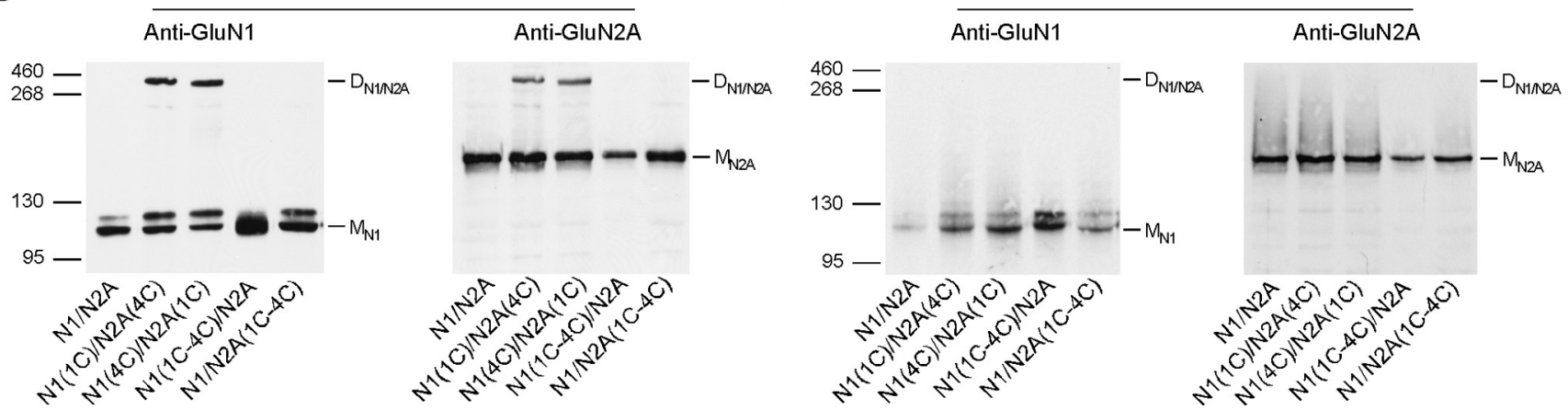

Figure 4. DTT-induced potentiation of agonist-activated currents is due to breakage of introduced disulfide cross-link. $A$, Schematics of cross-linking arrangements in cysteine-substituted receptors are shown in top-down view. In each receptor GuN1 subunits are black while GluN2A subunits are white. M3 helices and S2-M4 linkers are shown as circles while S1-M1 linkers are shown as ellipses, with disulfide bonds between different linkers indicated on the outside of the receptor. The selected focal pair for each cross-linking arrangement is listed below along with their abbreviated names. B, Membrane currents in oocytes injected with GluN1/GluN2A, GluN1(1C-4C)/GluN2A, GluN1(1C)/GluN2A, or GluN1(4C)/GluN2A. DTT (4 mM, gray bars) was applied for 120 s in the presence of competitive antagonists DCKA $(10 \mu \mathrm{M})$ and APV $(100 \mu \mathrm{M})$ (open boxes). In contrast to GluN1(1C-4C), receptors containing the individual cysteine substitutions, GluN1(1C)/GluN2A or GluN1(4C)/GluN2A, showed no significant DTT-induced current potentiation. C, Mean percentage potentiation in current amplitudes ( \pm SEM; $n \geq 5$ ) after DTT exposure for wild-type, the four focal pairs and receptors containing only one of the two substitutions in each pair. All experiments were done as in $A$. Solid bars indicate constructs showing significantly greater potentiation ( $p<$ 0.05 , Student's $t$ test) than GluN1/GluN2A $(6.0 \pm 7.0 \%, n=5)$. D, E, Immunoblots of membrane-purified proteins isolated from Xenopus oocytes injected with GluN1/GluN2A or the four focal pairs, assayed using antibodies against the N-terminal domain of GluN1 or GluN2A. Under nonreducing conditions (C), GluN1(1C)/GluN2A(4C) and GluN1(4C)/GluN2A(1C) formed a GluN1/GluN2A heterodimer $\left(D_{\mathrm{N} 1 / \mathrm{N} 2 \mathrm{~A}}\right)$. GluN1(1C-4C)/GluN2A and GluN1/GluN2A(1C-4C) showed only monomers $\left(\mathrm{M}_{\mathrm{N} 1}\right.$ or $\left.\mathrm{M}_{\mathrm{N} 2 \mathrm{~A}}\right)$. Under reducing conditions $(\boldsymbol{D})$, all constructs existed only as GluN1 (M $\left.\mathrm{M}_{\mathrm{N} 1}\right)$ or GluN2A $\left(\mathrm{M}_{\mathrm{N2A}}\right)$ monomers.

Table 1 summarizes the single-channel results including current amplitude (i), equilibrium open probability $\left(P_{\mathrm{o}}\right)$, mean closed time (MCT), and mean open time (MOT) for wild-type and the four focal pairs. In the absence of DTT, both intra- and inter-subunit crosslinked constructs showed significant decreases in $P_{\mathrm{o}}$ relative to wildtype $\left(P_{\mathrm{o}}=0.71 \pm 0.04, n=7\right)$. The most dramatic reduction in $P_{\mathrm{o}}$ occurred for the receptors with inter-subunit focal pairs, where it was reduced to $\sim 0.002$ for GluN1(1C)/GluN2A(4C) and $\sim 0.007$ for GluN1(4C)/GluN2A(1C) (Table 1). Reductions in $P_{\mathrm{o}}$ were less dramatic for the receptors with intra-subunit focal pairs and the effects were highly subunit-specific with $P_{\mathrm{o}}$ being reduced to $\sim 0.46$ in GluN1(1C-4C)/GluN2A and to $\sim 0.014$ in GluN1/GluN2A(1C4C). For all constructs, the drop in $P_{\mathrm{o}}$ could be largely accounted for by significant increases in MCT and decreases in MOT (Table 1). 
Under reducing conditions $(+\mathrm{DTT})$, wild-type as well as all focal pair receptors showed significant increases in $P_{\mathrm{o}}$ (relative to -DTT) with single-channel activity for most focal pair receptors approaching that of wild-type. A notable exception was GluN1(1C)/ GluN2A(4C) where DTT caused a significant increase in $P_{\mathrm{o}} \quad(\sim 0.002$ to $\sim 0.04$ ) but the + DTT $P_{\text {o }}$ was 22 -fold less than wild-type + DTT $(\sim 0.88)$. The reduced $P_{\mathrm{o}}$ in the + DTT condition for GluN1(1C)/GluN2A(4C) is likely due to one or both of the introduced cysteines themselves altering gating, an effect we do not explore further here. Nevertheless, our analysis of energetics will depend on the relative difference between the $-\mathrm{DTT}$ and +DTT conditions rather than the absolute gating properties in any one condition (see below). In this regard, focal pair receptors showed greater relative increases in $P_{\mathrm{o}}$ in the presence of DTT [increased 1.80 -fold for $\mathrm{N} 1(1 \mathrm{C}-4 \mathrm{C}) / \mathrm{N} 2 \mathrm{~A}$; 62 -fold for N1/N2A(1C-4C); 20-fold for $\mathrm{N} 1(1 \mathrm{C}) / \mathrm{N} 2 \mathrm{~A}(4 \mathrm{C}) ;$ and 92 -fold for $\mathrm{N} 1(4 \mathrm{C}) / \mathrm{N} 2 \mathrm{~A}(1 \mathrm{C})]$ than wild-type (1.14fold) suggesting that a major effect of DTT is the removal of constraints caused by the introduced cross-links.

In summary, these results suggest that constraining the peripheral linkers, either in an intra- or inter-subunit fashion, strongly impedes NMDA receptor gating indicating that a repositioning of these linkers is required for efficient gating. Further, the reduced $P_{\mathrm{o}}$ values shown by the constrained receptors were the result of both increases in MCT and decreases in MOT (Table 1). Hence, regions outside of the central pore axis can affect the relative stability of the closed and open states (Schmid et al., 2007; Talukder et al., 2010; Ren et al., 2012).

\section{Kinetic analysis of single-channel recordings}

To address how the intra- and inter-subunit constraints alter the energetics of gating, we performed kinetic and thermodynamic analyses on our single-channel results. Figure $6 \mathrm{~A}$ shows closed (top) and open (bottom) duration histograms and associated exponential fits (smooth lines) for wild-type GluN1/GluN2A either in the absence (solid line) or presence (dashed line) of DTT. For wild-type, five closed states best fit the data, as has been found previously (Wyllie et al., 1998; Auerbach and Zhou, 2005; Kussius and Popescu, 2009). Wild-type GluN1/GluN2A shows modal gating consisting of a brief open state and three longer lived open states (referred to as $\mathrm{O}_{2}, \mathrm{O}_{3}$, and $\mathrm{O}_{4}$ ) (Popescu and Auerbach, 2003). For our recordings, open distributions of wild-type were also best fit with four open states as were those for many individual records for the focal cysteine pairs (see Materials and Methods). However, in the absence of DTT, long duration openings were not always observed for receptors with focal cysteine pairs. We therefore fit open time histograms with just two open states, a brief open state $\left(\mathrm{O}_{1}\right)$ and a longer duration open state $\left(\mathrm{O}_{2}\right)$. Closed and open state occupancies $(\alpha)$ and time constants $(\tau)$ are shown in Tables 2 and 3, respectively.
Figure $6 B$ illustrates kinetic schemes (top) and the resultant energy landscapes (bottom) for wild-type GluN1/GluN2A recorded either in the absence (left) or presence (right) of DTT. For wild-type, as well as all four focal pairs, we used a kinetic model consisting of five closed and two open states (Kussius and Popescu, 2009; Talukder et al., 2011) that consists of a linear, "intraburst" $\mathrm{C}_{3}-\mathrm{C}_{2}-\mathrm{C}_{1}$ activation sequence with two off-pathway states $\left(\mathrm{C}_{5}\right.$ and $\mathrm{C}_{4}$, connected to $\mathrm{C}_{3}$ and $\mathrm{C}_{2}$, respectively) presumably representing desensitized states. In series with the $\mathrm{C}_{1}$ closed state is the brief $\mathrm{O}_{1}$ open state from which an additional, long duration $\mathrm{O}_{2}$ state arises (Popescu and Auerbach, 2003; Auerbach and Zhou, 2005) (see Discussion in terms of kinetic model used).

\section{Kinetic effects of constraining the GluN1 or GluN2A peripheral linkers on receptor gating}

Figure 7 illustrates closed and open duration fits $(A, C)$, kinetic schemes ( $B, D$, top) and the resultant energy landscapes (bottom) for the two intra-subunit focal pairs, GluN1(1C-4C)/GluN2A $(A, B)$ and GluN1/GluN2A(1C-4C) $(C, D)$. The kinetic rate constants for receptors containing the intra-subunit focal pairs in the absence of DTT showed widespread differences from wild-type (Fig. $7 B, D$, left). In general, the most notable difference was a significant reduction in the rates approaching the $O_{1}$ state with these effects consistently stronger in GluN2A(1C-4C). The reverse transition $\left(\mathrm{O}_{1}-\mathrm{C}_{1}\right)$ was also significantly faster for receptors with intra-subunit focal pairs, suggesting that the separation of these peripheral linkers may stabilize the open state. In the presence of DTT, these forward rates were increased and were generally comparable to those for wild-type + DTT (Fig. $7 B, D$, right). 
Table 1. Intra- or inter-subunit cross-linking of S1-M1 and S2-M4 linkers reduces NMDA receptor activation

\begin{tabular}{|c|c|c|c|c|c|}
\hline & Total events (\# of patches) & $i(\mathrm{pA})$ & $P_{0}$ & MCT (ms) & MOT (ms) \\
\hline \multicolumn{6}{|l|}{ N1/N2A } \\
\hline -DTT & $500,200(8)$ & $-7.6 \pm 0.3$ & $0.71 \pm 0.04$ & $3.0 \pm 0.4$ & $8.1 \pm 0.9$ \\
\hline +DTT & $890,000(7)$ & $-7.6 \pm 0.2$ & $0.88 \pm 0.04^{*}$ & $2.6 \pm 0.9$ & $21 \pm 4.4^{*}$ \\
\hline \multicolumn{6}{|c|}{$\mathrm{N} 1(1 \mathrm{C}-4 \mathrm{C}) / \mathrm{N} 2 \mathrm{~A}$} \\
\hline -DTT & 990,000 (5) & $-7.6 \pm 0.3$ & $0.46 \pm 0.05^{\wedge}$ & $5.7 \pm 0.7^{\wedge}$ & $4.8 \pm 0.4^{\wedge}$ \\
\hline +DTT & $890,000(4)$ & $-9.4 \pm 0.9$ & $0.83 \pm 0.05^{*}$ & $3.2 \pm 0.9$ & $17.7 \pm 3.3^{*}$ \\
\hline \multicolumn{6}{|c|}{$\mathrm{N} 1 / \mathrm{N} 2 \mathrm{~A}(1 \mathrm{C}-4 \mathrm{C})$} \\
\hline -DTT & $91,000(7)$ & $-11.7 \pm 0.7^{\wedge}$ & $0.014 \pm 0.006^{\wedge}$ & $270 \pm 70^{\wedge}$ & $1.2 \pm 0.2^{\wedge}$ \\
\hline +DTT & $200,000(4)$ & $-7.4 \pm 0.3^{*}$ & $0.87 \pm 0.06^{*}$ & $4.0 \pm 1.1^{*}$ & $40.7 \pm 10.1^{*}$ \\
\hline \multicolumn{6}{|c|}{$\mathrm{N} 1(1 \mathrm{C}) / \mathrm{N} 2 \mathrm{~A}(4 \mathrm{C})$} \\
\hline -DTT & $13,300(7)$ & $-6.9 \pm 0.5$ & $0.002 \pm 0.0005^{\wedge}$ & $620 \pm 280^{\wedge}$ & $0.38 \pm 0.06^{\wedge}$ \\
\hline +DTT & $204,000(4)$ & $-10.9 \pm 0.5^{*}$ & $0.04 \pm 0.005^{*}$ & $25.1 \pm 2.1^{*}$ & $0.90 \pm 0.09^{*}$ \\
\hline \multicolumn{6}{|c|}{$\mathrm{N} 1(4 \mathrm{C}) / \mathrm{N} 2 \mathrm{~A}(1 \mathrm{C})$} \\
\hline -DTT & $23,300(6)$ & $-10.9 \pm 0.9^{\wedge}$ & $0.007 \pm 0.0008^{\wedge}$ & $400 \pm 150^{\wedge}$ & $2.5 \pm 0.8^{\wedge}$ \\
\hline$+\mathrm{DTT}$ & $96,000(4)$ & $-9.1 \pm 0.6$ & $0.65 \pm 0.08^{*}$ & $9.1 \pm 3.5^{*}$ & $16.5 \pm 3.4^{*}$ \\
\hline
\end{tabular}

Mean values ( \pm SEM) for single-channel current amplitudes $(i)$, equilibrium open probability $\left(P_{0}\right), M C T$, and MOT. Single-channels recordings were analyzed in QuB (see Materials and Methods). $P_{0}$ is the fractional occupancy of the open states in the MIL fitted single-channel recordings. Significance is shown either relative to GluN1/GluN2A ( $\left.{ }^{*}\right)$ or to their respective non-DTT condition $\left({ }^{*}\right)(p<0.05$, Student's $t$ test). For numbering of residues, see Figure $4 A$.
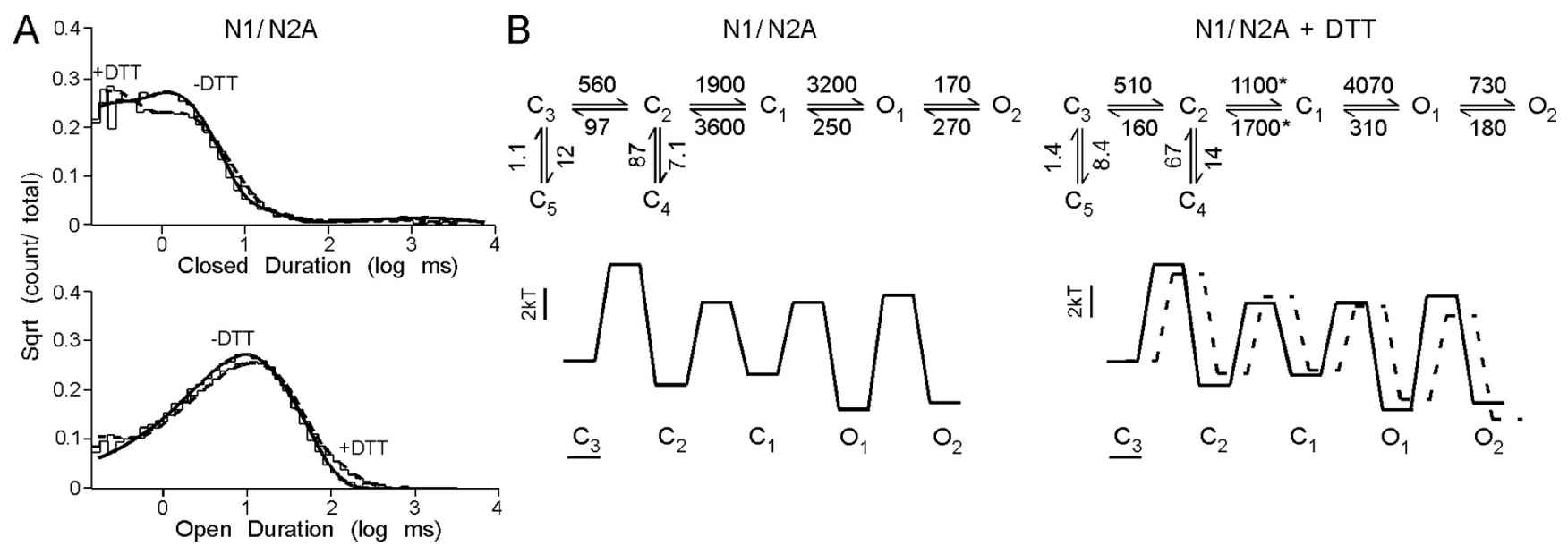

Figure 6. Kinetic modeling of GluN1/GluN2A in the absence and presence of DTT. A, Closed (top) and open (bottom) durations for GluN1/GluN2A in the absence (solid lines) or presence (dashed lines) of DTT. The closed-time distributions were both best fit with five closed states. The open-distributions were best fit with four open states, but are fitted here with two open states to permit comparisons across all tested constructs (see Materials and Methods). B, Top, Kinetic schemes for GluN1/GluN2A for the -DTT (left column) and + DTT (right column) conditions. Rate constants $\left(s^{-1}\right)$ are average values for a kinetic scheme with 5 closed and 2 open states (Table 4$) .{ }^{*}$ indicates rates significantly different from the $-D T T$ conditions ( $p<0.05$, Student's $t$ test). Number of patches: 8 (-DTT); 7 (+DTT). B , Bottom, Corresponding energetic landscapes for indicated kinetic schemes (see Materials and Methods). The energy landscapes are shown as black solid lines (wild-type, -DTT) or as black dashed lines (wild-type, +DTT). All landscapes were arbitrarily normalized to the $C_{3}$ state (underlined). The $x$-axis solely represents the gating states and does not carry a physical value. All plots have a unit scale of $2 \mathrm{kT}$.

\section{Intra-subunit constraints of the peripheral linkers restrict late gating transitions}

We initially constructed energy landscapes for each receptor under the different conditions (Fig. 7 B, D, bottom). In parallel with the kinetic rates, the difference in energy levels and barriers is greater for GluN1/GluN2A(1C-4C) (Fig. 7D, bottom, gray lines) than for GluN1(1C-4C)/N2A (Fig. 7B, bottom, gray lines) when compared with the wild-type landscape (Fig. $7 B, D$, bottom, thick lines). On the other hand, in the presence of DTT (Fig. 7 B, D, lower right panels, dashed lines), the landscapes have a generally similar profile, agreeing with the kinetic analysis.

The results presented so far highlight the effects of the intrasubunit constraints on reducing the efficacy of NMDA receptor gating. However, they do not quantify the energetic effects of constraints on specific kinetic transitions that depend on the difference in transition energy between the -DTT and +DTT conditions and must also consider the endogenous effects of DTT on GluN1/GluN2A receptors (Talukder et al., 2011) (Fig. 6). We therefore compared the free energy difference, referred to as $\Delta \Delta G$, between the $-\mathrm{DTT}\left(\Delta G_{-\mathrm{DTT}}\right)$ and $+\mathrm{DTT}\left(\Delta G_{+\mathrm{DTT}}\right)$ conditions for each cysteine-substituted receptor to that of GluN1/ GluN2A for each kinetic transition (significant differences highlighted by a " $\$$ " in each subsequent figure). To distinguish temporal effects on gating by the constraints, we compared $\Delta \Delta G$ values across different transitions for each individual receptor (highlighted by a “ $\ddagger$ ” in each subsequent figure). As presented in a subsequent section, we directly compared $\Delta \Delta G$ values between individual pairs of cysteine-substituted receptors to determine construct-specific differences. An advantage of this approach of comparing the difference between - DTT to +DTT in terms of energetic effects is that it compensates for any effect an individual cysteine substitution might have on receptor gating. For all of the above analyses, we focused on the direct pathway leading to channel opening $\left(\mathrm{C}_{3}-\mathrm{C}_{2}-\mathrm{C}_{1}-\mathrm{O}_{1}\right)$ and not on $\mathrm{O}_{1}-\mathrm{O}_{2}$ or off pathways $\left(\mathrm{C}_{3}-\mathrm{C}_{5}\right.$ and $\left.\mathrm{C}_{2}-\mathrm{C}_{4}\right)$ because of the limited number of events for these transitions, obscuring accurate analysis. 
Table 2. Closed state durations and occupancies for wild-type and receptors with focal cysteine pairs

\begin{tabular}{|c|c|c|c|c|c|}
\hline & $C_{1}$ & $C_{2}$ & $C_{3}$ & $C_{4}$ & $C_{5}$ \\
\hline \multicolumn{6}{|l|}{ N1/N2A } \\
\hline \multicolumn{6}{|l|}{$\tau(\mathrm{ms})$} \\
\hline -DTT & $0.13 \pm 0.002$ & $1.1 \pm 0.1$ & $2.5 \pm 0.36$ & $15.7 \pm 3.2$ & $1060 \pm 140$ \\
\hline +DTT & $0.7 \pm 0.01^{*}$ & $1.0 \pm 0.07$ & $2.7 \pm 0.2$ & $17.8 \pm 3.4$ & $880 \pm 150$ \\
\hline \multicolumn{6}{|l|}{$\alpha(\%)$} \\
\hline -DTT & $14.3 \pm 1.2$ & $53.7 \pm 5.9$ & $30.9 \pm 6.4$ & $0.85 \pm 0.2$ & $0.15 \pm 0.02$ \\
\hline$+\mathrm{DTT}$ & $39.9 \pm 2.7^{*}$ & $35.4 \pm 2.4^{*}$ & $23.4 \pm 3.4$ & $1.1 \pm 0.31$ & $0.13 \pm 0.05$ \\
\hline \multirow{2}{*}{\multicolumn{6}{|c|}{$\begin{array}{c}\mathrm{N} 1(1 \mathrm{C}-4 \mathrm{C}) / \mathrm{N} 2 \mathrm{~A} \\
\tau(\mathrm{ms})\end{array}$}} \\
\hline & & & & & \\
\hline$-\mathrm{DTT}$ & $0.18 \pm 0.01^{\wedge}$ & $2.1 \pm 0.21^{\wedge}$ & $6.0 \pm 0.76^{\wedge}$ & $27.1 \pm 6.7$ & $450 \pm 70^{\wedge}$ \\
\hline +DTT & $0.16 \pm 0.01$ & $1.2 \pm 0.1^{*}$ & $3.2 \pm 0.3^{*}$ & $29.1 \pm 5.5$ & $1180 \pm 348$ \\
\hline \multicolumn{6}{|l|}{$\alpha(\%)$} \\
\hline -DIT & $15.1 \pm 1.4$ & $33.2 \pm 4.3^{\wedge}$ & $47.0 \pm 3.6$ & $4.4 \pm 1.52$ & $0.26 \pm 0.05$ \\
\hline +DTT & $30.3 \pm 3.7^{*}$ & $46.2 \pm 3.0^{*}$ & $22.6 \pm 6.1^{*}$ & $0.73 \pm 0.04$ & $0.13 \pm 0.03$ \\
\hline \multirow{2}{*}{\multicolumn{6}{|c|}{$\begin{array}{c}\mathrm{N} 1 / \mathrm{N} 2 \mathrm{~A}(1 \mathrm{C}-4 \mathrm{C}) \\
\tau(\mathrm{ms})\end{array}$}} \\
\hline & & & & & \\
\hline -DTT & $0.2 \pm 0.02^{\wedge}$ & $39.4 \pm 14^{\wedge}$ & $130 \pm 37^{\wedge}$ & $1200 \pm 430^{\circ}$ & $16000 \pm 8900$ \\
\hline +DIT & $0.15 \pm 0.01$ & $1.1 \pm 0.2^{*}$ & $3.8 \pm 0.85^{*}$ & $65 \pm 39.4^{*}$ & $1490 \pm 360$ \\
\hline \multicolumn{6}{|l|}{$\alpha(\%)$} \\
\hline -DIT & $3.9 \pm 0.9^{\wedge}$ & $22.9 \pm 6.2^{\wedge}$ & $60.7 \pm 4.6^{\wedge}$ & $10.2 \pm 1.7^{\wedge}$ & $2.2 \pm 0.9^{\wedge}$ \\
\hline$+\mathrm{DTT}$ & $47.4 \pm 4.2^{*}$ & $37.9 \pm 2.7$ & $13.6 \pm 4.9^{*}$ & $0.84 \pm 0.5^{*}$ & $0.20 \pm 0.05$ \\
\hline \multirow{2}{*}{\multicolumn{6}{|c|}{$\begin{array}{l}\mathrm{N} 1(1 \mathrm{C}) / \mathrm{N} 2 \mathrm{~A}(4 \mathrm{C}) \\
\tau(\mathrm{ms})\end{array}$}} \\
\hline & & & & & \\
\hline -DTT & $0.33 \pm 0.08$ & $6.6 \pm 2.3^{\wedge}$ & $96 \pm 26^{\wedge}$ & $400 \pm 90^{\wedge}$ & $1700 \pm 740$ \\
\hline +DIT & $0.19 \pm 0.07$ & $3.8 \pm 1.1$ & $12.5 \pm 2.3^{*}$ & $91.2 \pm 23.3^{*}$ & $1140 \pm 90$ \\
\hline \multicolumn{6}{|l|}{$\alpha(\%)$} \\
\hline -DTT & $5.6 \pm 1.8^{\wedge}$ & $9.1 \pm 2.3^{\wedge}$ & $23.9 \pm 5.8^{\wedge}$ & $39.6 \pm 6.5^{\wedge}$ & $21.8 \pm 7.4^{\wedge}$ \\
\hline$+\mathrm{DTT}$ & $4.1 \pm 1.2$ & $34.1 \pm 8.9$ & $57.5 \pm 9.0^{*}$ & $3.1 \pm 0.86^{*}$ & $1.3 \pm 0.10^{*}$ \\
\hline \multirow{2}{*}{\multicolumn{6}{|c|}{$\begin{array}{l}\mathrm{N} 1(4 \mathrm{C}) / \mathrm{N} 2 \mathrm{~A}(1 \mathrm{C}) \\
\tau(\mathrm{ms})\end{array}$}} \\
\hline & & & & & \\
\hline -DTT & $0.24 \pm 0.03^{\wedge}$ & $4.9 \pm 1.2^{\wedge}$ & $25.2 \pm 5.8^{\wedge}$ & $470 \pm 95^{\wedge}$ & $2380 \pm 570$ \\
\hline +DTT & $0.17 \pm 0.01$ & $1.0 \pm 0.15^{*}$ & $4.0 \pm 1.2^{*}$ & $150 \pm 94^{*}$ & $2100 \pm 1500$ \\
\hline \multicolumn{6}{|l|}{$\alpha(\%)$} \\
\hline -DTT & $10.9 \pm 1.9^{\wedge}$ & $25.5 \pm 6.0^{\wedge}$ & $26.1 \pm 6.1^{\wedge}$ & $21.7 \pm 3.1^{\wedge}$ & $15.8 \pm 5.9^{\wedge}$ \\
\hline +DTT & $31.5 \pm 6.8$ & $48.6 \pm 3.2^{*}$ & $17.4 \pm 8.8$ & $1.6 \pm 0.28^{*}$ & $0.98 \pm 0.62$ \\
\hline
\end{tabular}

Mean values ( \pm SEM) for closed state durations $(\tau, \mathrm{ms})$ and occupancies $(\alpha, \%)$. Values were derived after fitting idealized single-channel records to a five-closed and two-open state kinetic scheme (see Materials and Methods). Significance is shown either relative to GluN1/GluN2A ( $\left.{ }^{*}\right)$ or to their respective non-DTT condition $\left(^{*}\right)(p<0.05$, Student's t test).

Table 3. Open state durations and occupancies for wild-type and receptors with focal cysteine pairs

\begin{tabular}{|c|c|c|c|c|}
\hline & $\tau_{01}, \mathrm{~ms}$ & $\alpha_{01}, \%$ & $\tau_{02}, \mathrm{~ms}$ & $\alpha_{02}, \%$ \\
\hline \multicolumn{5}{|l|}{ N1/N2A } \\
\hline -DTT & $4.4 \pm 0.87$ & $47.9 \pm 7.9$ & $11.3 \pm 1.3$ & $52.1 \pm 7.9$ \\
\hline +DTT & $4.2 \pm 1.4$ & $31.4 \pm 9.8^{*}$ & $26.4 \pm 3.7^{*}$ & $68.6 \pm 9.8$ \\
\hline \multicolumn{5}{|c|}{$\mathrm{N} 1(1 \mathrm{C}-4 \mathrm{C})-\mathrm{N} 2 \mathrm{~A}$} \\
\hline -DTT & $0.7 \pm 0.5^{\wedge}$ & $20.5 \pm 7.0^{\wedge}$ & $5.7 \pm 0.4^{\wedge}$ & $79.6 \pm 7.0^{\wedge}$ \\
\hline +DTT & $2.1 \pm 1.7$ & $19.1 \pm 13.5$ & $21.1 \pm 3.5^{*}$ & $80.7 \pm 13.4$ \\
\hline \multicolumn{5}{|c|}{ N1/N2A(1C-4C) } \\
\hline -DTT & $0.7 \pm 0.1^{\wedge}$ & $70.7 \pm 10.9$ & $3.2 \pm 1.2^{\wedge}$ & $29.3 \pm 10.9$ \\
\hline +DTT & $2.2 \pm 1.1$ & $14.9 \pm 7.1^{*}$ & $45.2 \pm 9.9^{*}$ & $85.11 \pm 7.12^{*}$ \\
\hline \multicolumn{5}{|c|}{$\mathrm{N} 1(1 \mathrm{C}) / \mathrm{N} 2 \mathrm{~A}(4 \mathrm{C})$} \\
\hline -DTT & $0.15 \pm 0.01^{\wedge}$ & $81 \pm 3.1^{\wedge}$ & $1.5 \pm 0.3^{\wedge}$ & $18.9 \pm 3.1^{\wedge}$ \\
\hline +DTT & $0.57 \pm 0.14^{*}$ & $58.4 \pm 13.7$ & $1.8 \pm 0.5$ & $41.6 \pm 13.7$ \\
\hline \multicolumn{5}{|c|}{$\mathrm{N} 1(4 \mathrm{C}) / \mathrm{N} 2 \mathrm{~A}(1 \mathrm{C})$} \\
\hline -DTT & $0.3 \pm 0.08^{\wedge}$ & $47.1 \pm 3.6^{\wedge}$ & $4.5 \pm 1.4^{\wedge}$ & $52.9 \pm 3.6^{\wedge}$ \\
\hline +DTT & $0.7 \pm 0.3$ & $7.5 \pm 1.24^{*}$ & $17.7 \pm 3.6^{*}$ & $92.5 \pm 1.2^{*}$ \\
\hline
\end{tabular}

Mean values ( \pm SEM) for open state durations $(\tau, \mathrm{ms})$ and occupancies $(\alpha, \%)$. Significance is shown either relative to GluN1/GluN2A ( $\left.{ }^{\wedge}\right)$ or to their respective non-DTT condition $\left({ }^{*}\right)(p<0.05$, Student's t test).

Previous studies have shown that the major endogenous effect of DTT on GluN1/GluN2A receptors is to increase the occupancy of long-lived open states (Talukder et al., 2011). In terms of energetic effects (Fig. 7E), this increase in occupancy is manifested as a significant difference in energy between the -DTT and
+ DTT conditions for only the $\mathrm{O}_{1}-\mathrm{O}_{2}$ transition (highlighted by a “*”). Because this reaction became more energetically favorable in the presence of DTT, it is manifested as a negative $\Delta \Delta G$.

Intra-subunit constraints of the peripheral linkers in either GluN1 or GluN2A showed no energetic effect on the early $\mathrm{C}_{3}-\mathrm{C}_{2}$ gating transition (Fig. 7E). However, for GluN1/GluN2A(1C$4 \mathrm{C}), \Delta \Delta G$ values were significantly different from wild-type for the $\mathrm{C}_{2}-\mathrm{C}_{1}$ and $\mathrm{C}_{1}-\mathrm{O}_{1}$ transitions. Further, for GluN1/ GluN2A(1C-4C), the $\mathrm{C}_{2}-\mathrm{C}_{1}$ and $\mathrm{C}_{1}-\mathrm{O}_{1} \Delta \Delta G$ values were significantly different from that of the $\mathrm{C}_{3}-\mathrm{C}_{2}$ transition, highlighting a potential temporal dependence for movements of the GluN2A peripheral linkers. The constraint in the GluN1 subunit [GluN1(1C-4C)/GluN2A] also restricted gating transitions approaching channel opening, but the $\Delta \Delta G$ values were only significantly different from wild-type for the $\mathrm{C}_{1}-\mathrm{O}_{1}$ transition. Hence, the physical constraint between the peripheral linkers in the GluN1 and GluN2A subunits significantly restrict gating transitions nearing the open state but they do not appear to be equivalent in their actions.

\section{Inter-subunit constraints of the peripheral linkers have} widespread effects on gating transitions

Figure 8 illustrates closed and open duration fits $(A, C)$, kinetic schemes ( $B, D$, top) and energetic landscapes (bottom) for receptors with inter-subunit focal pairs of cysteines, GluN1(1C)/ GluN2A(4C) $(A, B)$ and GluN1(1C)/GluN2A(4C) $(C, D)$. Similar 
Table 4. Kinetic rate constants for wild-type and receptors with focal cysteine pairs

\begin{tabular}{|c|c|c|c|c|c|c|}
\hline & $\mathrm{C}_{3}-\mathrm{C}_{2}$ & $C_{2}-C_{1}$ & $C_{1}-0_{1}$ & $C_{3}-C_{5}$ & $C_{2}-C_{4}$ & $0_{1}-0_{2}$ \\
\hline \multicolumn{7}{|l|}{ N1/N2A } \\
\hline \multicolumn{7}{|l|}{ Forward } \\
\hline -DTT & $560 \pm 100$ & $1900 \pm 140$ & $3200 \pm 190$ & $12 \pm 2.8$ & $7.1 \pm 2.1$ & $170 \pm 140$ \\
\hline +DTT & $510 \pm 42$ & $1100 \pm 62^{*}$ & $4070 \pm 280$ & $8.4 \pm 3.2$ & $14 \pm 3.7$ & $730 \pm 450$ \\
\hline \multicolumn{7}{|l|}{ Reverse } \\
\hline -DTT & $97 \pm 20$ & $3600 \pm 140$ & $250 \pm 34$ & $1.1 \pm 0.2$ & $87 \pm 18$ & $270 \pm 140$ \\
\hline +DTT & $160 \pm 40$ & $1700 \pm 120^{*}$ & $310 \pm 130$ & $1.4 \pm 0.3$ & $67 \pm 9.2$ & $180 \pm 50$ \\
\hline \multicolumn{7}{|l|}{$\mathrm{N} 1(1 \mathrm{C}-4 \mathrm{C}) / \mathrm{N} 2 \mathrm{~A}$} \\
\hline \multicolumn{7}{|l|}{ Forward } \\
\hline -DIT & $300 \pm 50^{\wedge}$ & $900 \pm 140^{\wedge}$ & $2100 \pm 140^{\wedge}$ & $3.6 \pm 1.0^{\wedge}$ & $9.5 \pm 1.4$ & $2500 \pm 680^{\wedge}$ \\
\hline +DTT & $400 \pm 50$ & $1200 \pm 56$ & $3600 \pm 350^{*}$ & $9.2 \pm 3.6$ & $7.9 \pm 1.8^{\#}$ & $1900 \pm 1040$ \\
\hline \multicolumn{7}{|l|}{ Reverse } \\
\hline -DIT & $89 \pm 13$ & $3200 \pm 130^{\wedge}$ & $1400 \pm 290^{\wedge}$ & $2.7 \pm 0.6$ & $51 \pm 14$ & $580 \pm 90$ \\
\hline +DTT & $86 \pm 9.9$ & $2200 \pm 170^{* \#}$ & $540 \pm 270$ & $1.2 \pm 0.4$ & $38 \pm 7.1$ & $400 \pm 120$ \\
\hline \multicolumn{7}{|l|}{$\mathrm{N} 1 / \mathrm{N} 2 \mathrm{~A}(1 \mathrm{C}-4 \mathrm{C})$} \\
\hline \multicolumn{7}{|l|}{ Forward } \\
\hline -DTT & $100 \pm 63^{\wedge}$ & $240 \pm 46^{\wedge}$ & $670 \pm 190^{\wedge}$ & $1.3 \pm 0.7^{\wedge}$ & $3.1 \pm 1.8$ & $120 \pm 47$ \\
\hline +DTT & $390 \pm 120$ & $1100 \pm 140^{*}$ & $4400 \pm 1200^{*}$ & $16 \pm 6.9$ & $10 \pm 2.7$ & $490 \pm 160$ \\
\hline \multicolumn{7}{|l|}{ Reverse } \\
\hline -DIT & $80 \pm 56$ & $5010 \pm 730$ & $1500 \pm 310$ & $0.5 \pm 0.3$ & $3.8 \pm 1.6^{\wedge}$ & $630 \pm 140$ \\
\hline +DTT & $100 \pm 30$ & $1300 \pm 60^{* \#}$ & $190 \pm 14^{*}$ & $0.9 \pm 0.2$ & $41 \pm 16$ & $160 \pm 30^{*}$ \\
\hline \multicolumn{7}{|l|}{$\mathrm{N} 1(1 \mathrm{C}) / \mathrm{N} 2 \mathrm{~A}(4 \mathrm{C})$} \\
\hline \multicolumn{7}{|l|}{ Forward } \\
\hline -DIT & $31 \pm 15^{\wedge}$ & $570 \pm 210^{\wedge}$ & $1900 \pm 830$ & $1.3 \pm 0.5$ & $250 \pm 170$ & $390 \pm 56$ \\
\hline +DTT & $190 \pm 60^{\#}$ & $1200 \pm 200$ & $1060 \pm 240^{\#}$ & $5.9 \pm 1.6$ & $4.7 \pm 1.3^{\#}$ & $240 \pm 120$ \\
\hline \multicolumn{7}{|l|}{ Reverse } \\
\hline -DTT & $104 \pm 74$ & $5300 \pm 1800$ & $7050 \pm 800^{\circ}$ & $1.5 \pm 0.3$ & $50 \pm 18$ & $1400 \pm 470^{\wedge}$ \\
\hline +DTT & $120 \pm 66$ & $5090 \pm 1450$ & $1600 \pm 250^{* \#}$ & $0.9 \pm 0.05$ & $13 \pm 2.8$ & $980 \pm 280$ \\
\hline \multicolumn{7}{|l|}{$\mathrm{N} 1(4 \mathrm{C}) / \mathrm{N} 2 \mathrm{~A}(1 \mathrm{C})$} \\
\hline \multicolumn{7}{|l|}{ Forward } \\
\hline -DTT & $88 \pm 22^{\wedge}$ & $370 \pm 27^{\wedge}$ & $1400 \pm 250^{\wedge}$ & $8.8 \pm 2.6$ & $87 \pm 58$ & $1200 \pm 200^{\wedge}$ \\
\hline +DTT & $350 \pm 110$ & $1500 \pm 230^{*}$ & $3500 \pm 460^{*}$ & $44 \pm 25$ & $26 \pm 4.9$ & $1460 \pm 580$ \\
\hline \multicolumn{7}{|l|}{ Reverse } \\
\hline -DTT & $145 \pm 70$ & $3200 \pm 300$ & $2900 \pm 410^{\wedge}$ & $1.4 \pm 0.8$ & $5.1 \pm 1.9^{\wedge}$ & $510 \pm 120$ \\
\hline +DTT & $130 \pm 32$ & $1900 \pm 210^{*}$ & $450 \pm 160^{*}$ & $2.3 \pm 1.2$ & $27 \pm 14$ & $480 \pm 90^{\#}$ \\
\hline
\end{tabular}

Mean values ( \pm SEM) for kinetic rate constants $\left(s^{-1}\right)$ for a $5\left(-20\right.$ gating model. Significance is shown either relative to GluN1/GluN2A $\left(^{\wedge}\right)$ or to their respective non-DTT condition $\left({ }^{*}\right)(p<0.05$, Student's $t$ test).

to the intra-subunit focal pairs, the forward rate constants approaching channel opening for the inter-subunit focal pairs were significantly reduced and the reverse $\mathrm{O}_{1}-\mathrm{C}_{1}$ rate constant was significantly increased relative to wild-type. All of the forward rates significantly increased in the +DTT condition, except for the forward $\mathrm{C}_{1}-\mathrm{O}_{1}$ transition for GluN1(1C)/GluN2A(4C). This GluN1(1C)/GluN2A(4C) construct showed a low $P_{\mathrm{o}}$ even in the presence of DTT (Table 1) that presumably reflects an effect of the cysteine substitutions themselves. The most notable feature of this construct is the large decrease in the reverse $\mathrm{O}_{1}-\mathrm{C}_{1}$ transition suggesting a potential role of these linkers in stabilizing the open state.

The energy landscapes (Fig. $8 B, D$, bottom) highlight the strong energetic effects of the inter-subunit constraints across all gating transitions. Superficially, because they are scaled the same, these landscapes highlight the differences between the intra- and inter-subunit constraints of the peripheral linkers (Fig. 7, compare $B, D)$.

Figure $8 E$ summarizes the energetic effects on gating arising from inter-subunit constraints of the peripheral linkers. For GluN1(1C)/GluN2A(4C), there was a significant difference in $\Delta \Delta G$ relative to wild-type only during the $\mathrm{C}_{3}-\mathrm{C}_{2}$ transition. On the other hand, for GluN1(4C)/GluN2A(1C), the $\Delta \Delta G$ values were significantly different relative to wild-type for each transition before opening. In addition, $\Delta \Delta G$ values were significantly different between the $\mathrm{C}_{1}-\mathrm{O}_{1}$ and $\mathrm{C}_{3}-\mathrm{C}_{2}$ transitions. Overall, both constructs showed major effects relative to wild-type during the early $\mathrm{C}_{3}-\mathrm{C}_{2}$ transition while only GluN1(4C)/GluN2A(1C) significantly affected later gating transitions.

\section{Asynchronous dynamics of the peripheral linkers during NMDA receptor activation}

NMDA receptor gating was significantly dependent on the conformational freedom of the peripheral linkers both within (Fig. 7) and between (Fig. 8) subunits when compared with wild-type. To determine whether there were constructspecific gating effects, we contrasted the $\Delta \Delta G$ values between pairs of constructs (Fig. $9 A$ ). During the $\mathrm{C}_{3}-\mathrm{C}_{2}$ transition, the inter-subunit GluN1(1C)/GluN2A(4C) construct showed a significant difference in $\Delta \Delta G$ compared with both the intraGluN1 and intra-GluN2A constrained constructs. On the other hand, during the $\mathrm{C}_{2}-\mathrm{C}_{1}$ transition, the intra-subunit GluN1/GluN2A(1C-4C) construct had a significantly different $\Delta \Delta G$ value compared with the inter-subunit GluN1(1C)/ GluN2A(4C) construct. Last, for the $\mathrm{C}_{1}-\mathrm{O}_{1}$ transition, the GluN1/GluN2A(1C-4C) and GluN1(4C)/GluN2A(1C) receptors showed greater differences in $\Delta \Delta G$ than that of the GluN1(1C)/GluN2A(4C) construct. Thus, the $\Delta \Delta G$ values between constructs are not equivalent during the different receptor activation steps, indicating specific peripheral linker rearrangements occur asynchronously relative to one another. 

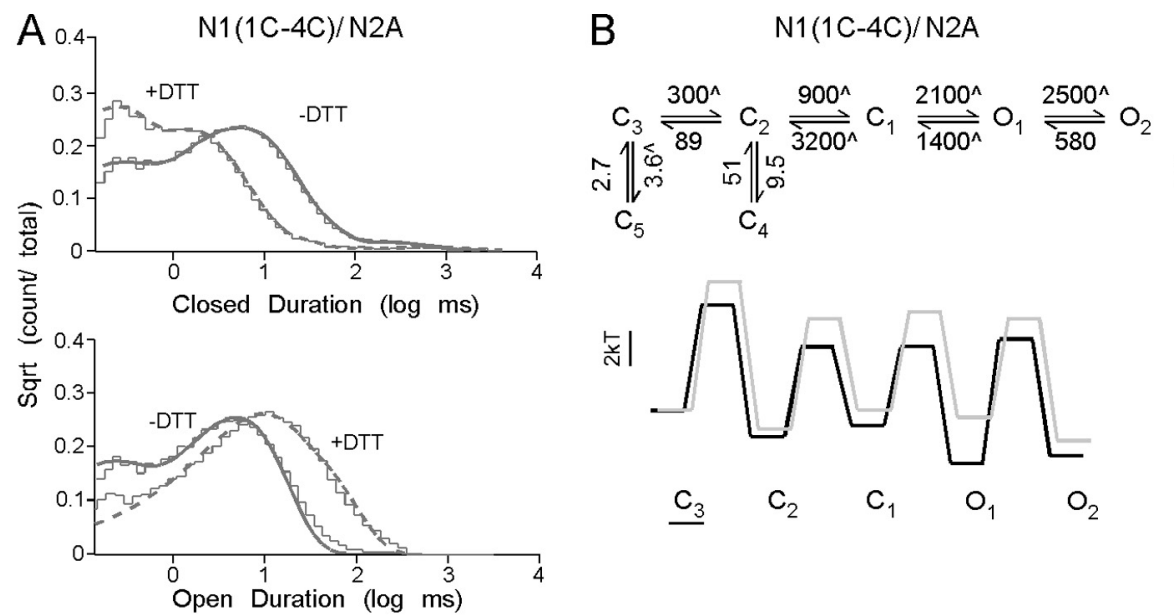

$$
\mathrm{N} 1(1 \mathrm{C}-4 \mathrm{C}) / \mathrm{N} 2 \mathrm{~A}+\mathrm{DTT}
$$
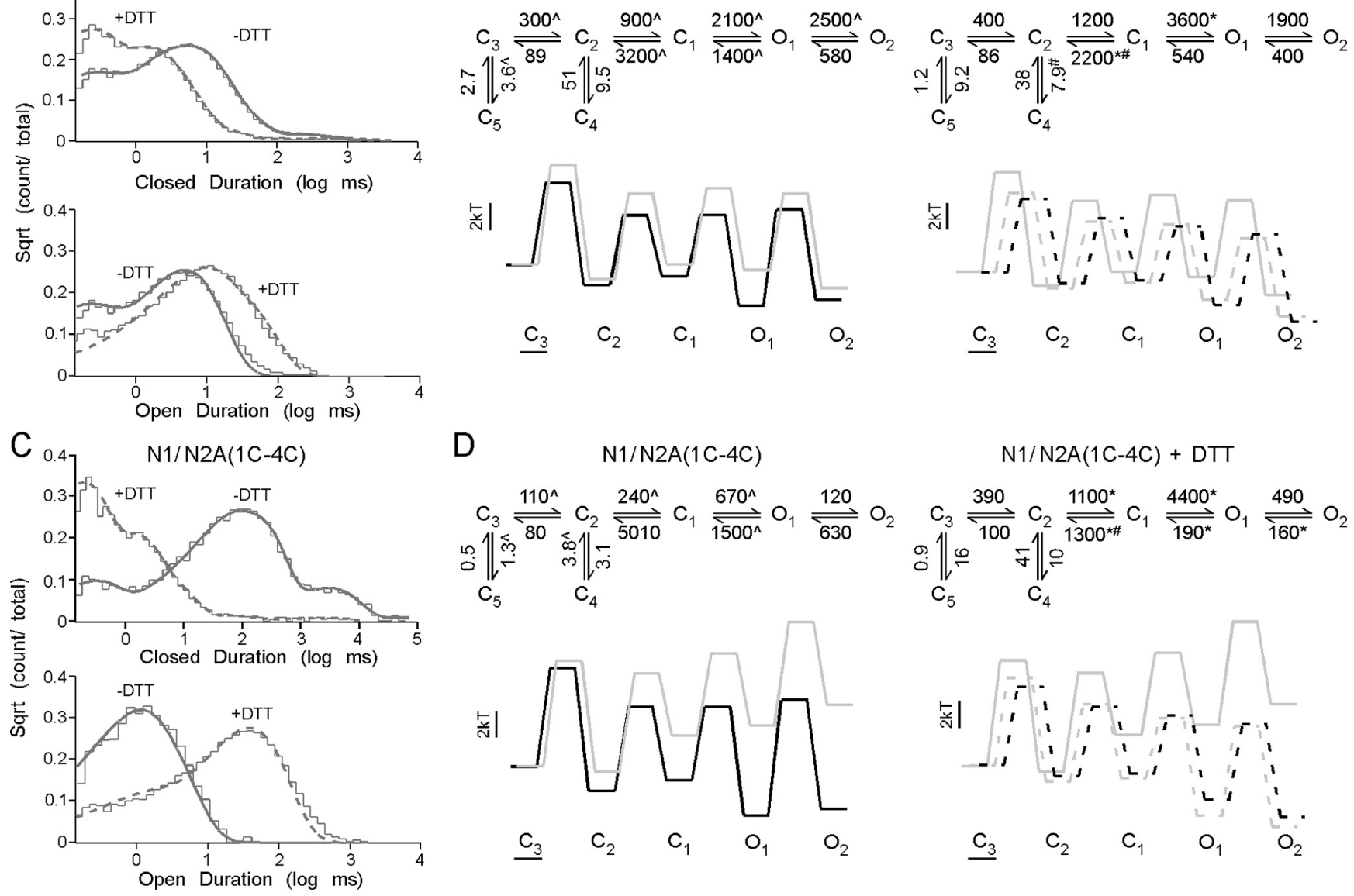

D

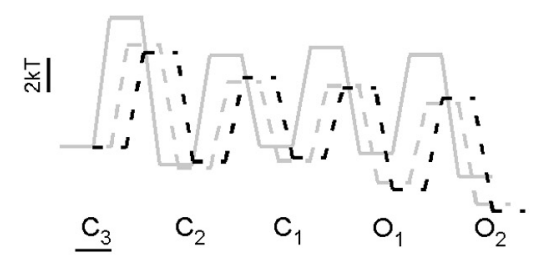

$\mathrm{N} 1 / \mathrm{N} 2 \mathrm{~A}(1 \mathrm{C}-4 \mathrm{C})$
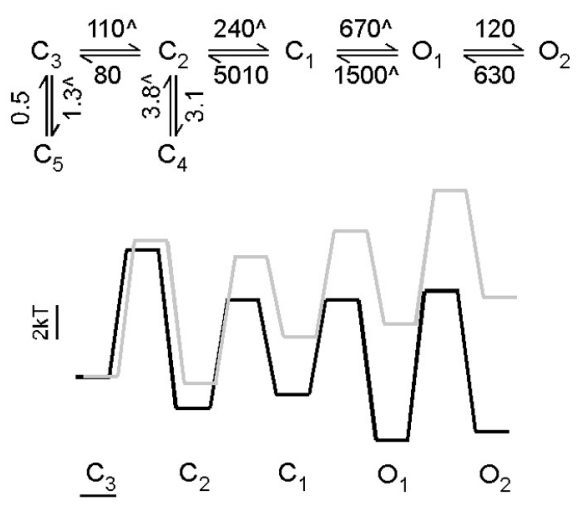

$\mathrm{E}$

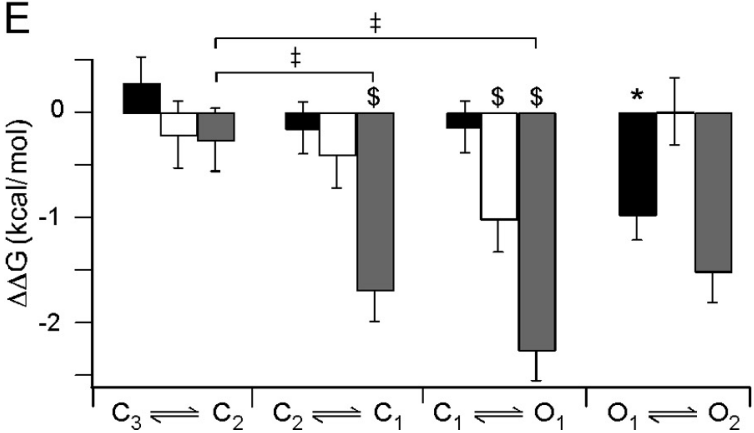

Figure 7. Intra-subunit cross-linking of S1-M1 and S2-M4 disrupts late gating transitions. $A, C$, Closed (top) and open (bottom) durations for GluN1(1C-4C)/GluN2A (A) and GluN1/GluN2A(1C4C)/GluN2A ( $\boldsymbol{C}$ ) in the absence (solid gray lines) or presence (dashed gray lines) of DTT. Fits are as described in Figure $6 A$. $\boldsymbol{B}, \boldsymbol{D}$, Top, Kinetic schemes for GluN1(1C-4C)/GluN2A (B) and GluN1/ GluN2A (1C-4C) (D) for the -DTT (left column) and +DTT (right column) conditions. Rate constants $\left(\mathrm{s}^{-1}\right.$ ) are average values for a kinetic scheme with 5 closed and 2 open states (Table 4). For the left column, " indicates rates significantly different from GluN1/GluN2A; for the right column, ${ }^{\#}$ indicates rates significantly different from GluN1/GluN2A + DTT while * indicates rates significantly different from the respective -DTT conditions ( $p<0.05$, Student's $t$ test). Number of patches: GluN1(1C-4C)/GluN2A, 5 ( $-D T T), 4$ ( +DTT); GluN1/GluN2A(1C-4C), 7 (-DTT), 4 ( + DTT). B, D, Bottom, Corresponding energetic landscapes for indicated kinetic schemes. The energy landscapes are shown as black continuous lines (wild-type, $-D T T)$, gray continuous lines (focal pairs, $-D T T$ ), black dashed lines (wild-type, $+D T T$ ), and gray dashed lines (focal pairs, + DTT). All landscapes are displayed as described in Figure $6 B$. $E$, Mean $\Delta \Delta G( \pm$ SEM) between the $+D T T(\Delta G$, DTT $)$ and -DTT $\left(\Delta G_{\text {-DTT }}\right)$ conditions for GluN1/GluN2A, GluN1(1C-4C)/GluN2A, and GluN1/GluN2A(1C-4C) for each gating transition (see Materials and Methods). * indicates significant differences between $\Delta G_{+D T T}$ and $\Delta G_{-D T T}$ for GluN1/GluN2A during the $0_{1}-0_{2}$ transition ( $p<0.05$, Student's $t$ test). \$ indicates significant differences between a cysteine-substituted receptor and wild-type $(p<0.05$, Student's $t$ test) for a specific transition. ‡ indicates significant differences between a pair of transitions within a construct ( $p<0.05$, Student's $t$ test).

\section{Discussion}

Pore opening is the key step in NMDA receptor gating that allows the flux of ions including $\mathrm{Ca}^{2+}$ across the membrane. This step occurs in a largely concerted fashion within the current limits of resolution (Schorge et al., 2005; Kussius and Popescu, 2009; Traynelis et al., 2010). In contrast, the highly homologous AMPA receptor subtype gates in a subunit-specific manner (Rosenmund et al., 1998; Smith and Howe, 2000). For NMDA receptors, con- certed pore opening could arise by the conformational change induced by agonist binding in the four subunits (Regalado et al., 2001) propagating in a synchronous manner to the ion channel gate, which is presumably located near the extracellular end of the M3 helices (Chang and Kuo, 2008; Sobolevsky et al., 2009). We find that the peripheral linkers that tightly surround the centrally located gating elements must rearrange for efficient gating to occur in NMDA receptors but that these rearrangements are not 


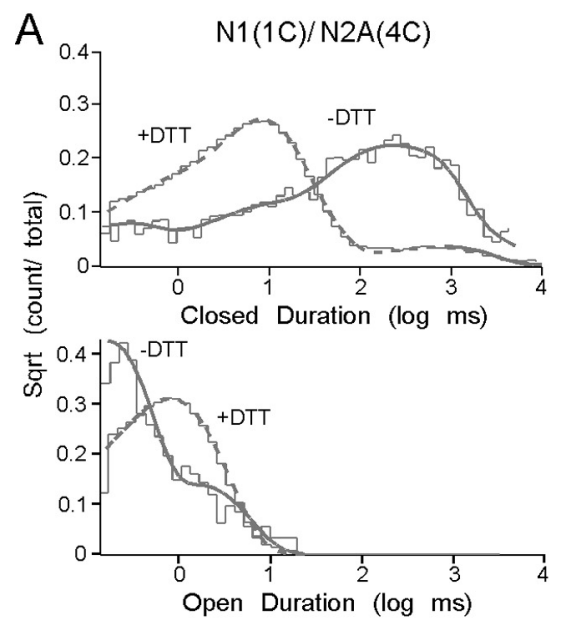

B

$\mathrm{N} 1(1 \mathrm{C}) / \mathrm{N} 2 \mathrm{~A}(4 \mathrm{C})$

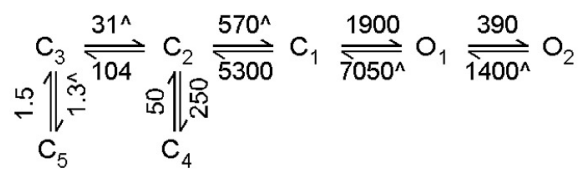

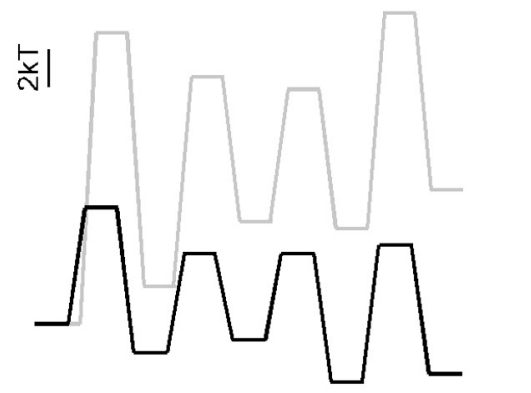

$\begin{array}{lllll}\mathrm{C}_{3} & \mathrm{C}_{2} & \mathrm{C}_{1} & \mathrm{O}_{1} & \mathrm{O}_{2}\end{array}$

D N1(4C)/N2A(1C)
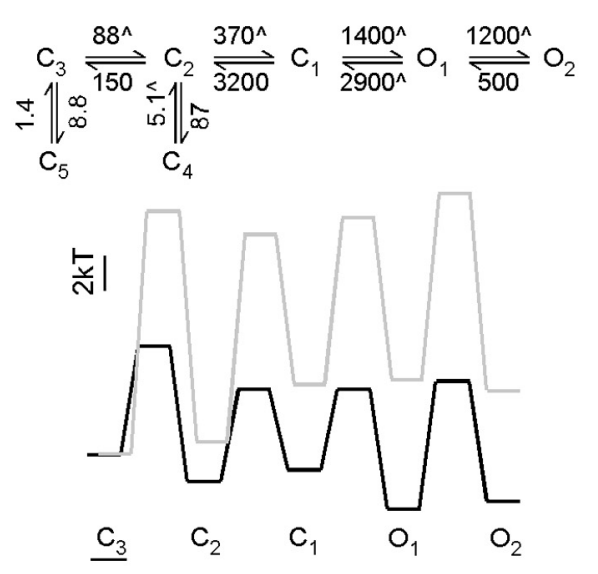

$\mathrm{N} 1(1 \mathrm{C}) / \mathrm{N} 2 \mathrm{~A}(4 \mathrm{C})+\mathrm{DTT}$

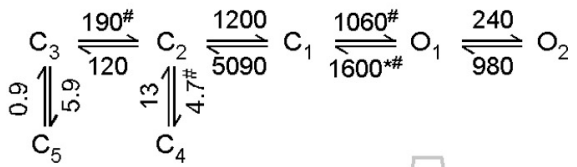

$\mathrm{C}_{3} \underset{120}{\rightleftharpoons} \mathrm{C}_{2} \underset{5090}{\rightleftharpoons} \mathrm{C}_{1} \underset{1600^{* \#}}{\stackrel{\rightleftharpoons}{\rightleftharpoons}} \mathrm{O}_{1} \underset{980}{\stackrel{240}{\rightleftharpoons}} \mathrm{O}_{2}$

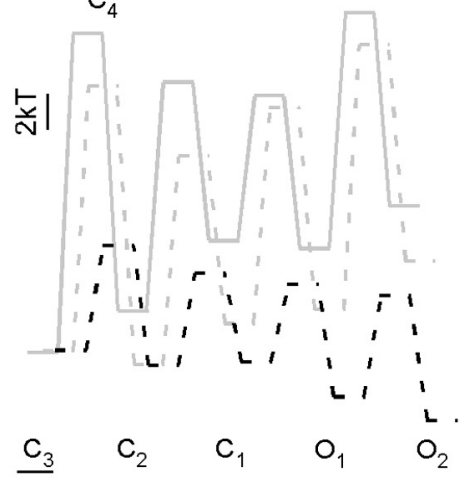

$\mathrm{N} 1(4 \mathrm{C}) / \mathrm{N} 2 \mathrm{~A}(1 \mathrm{C})+\mathrm{DTT}$
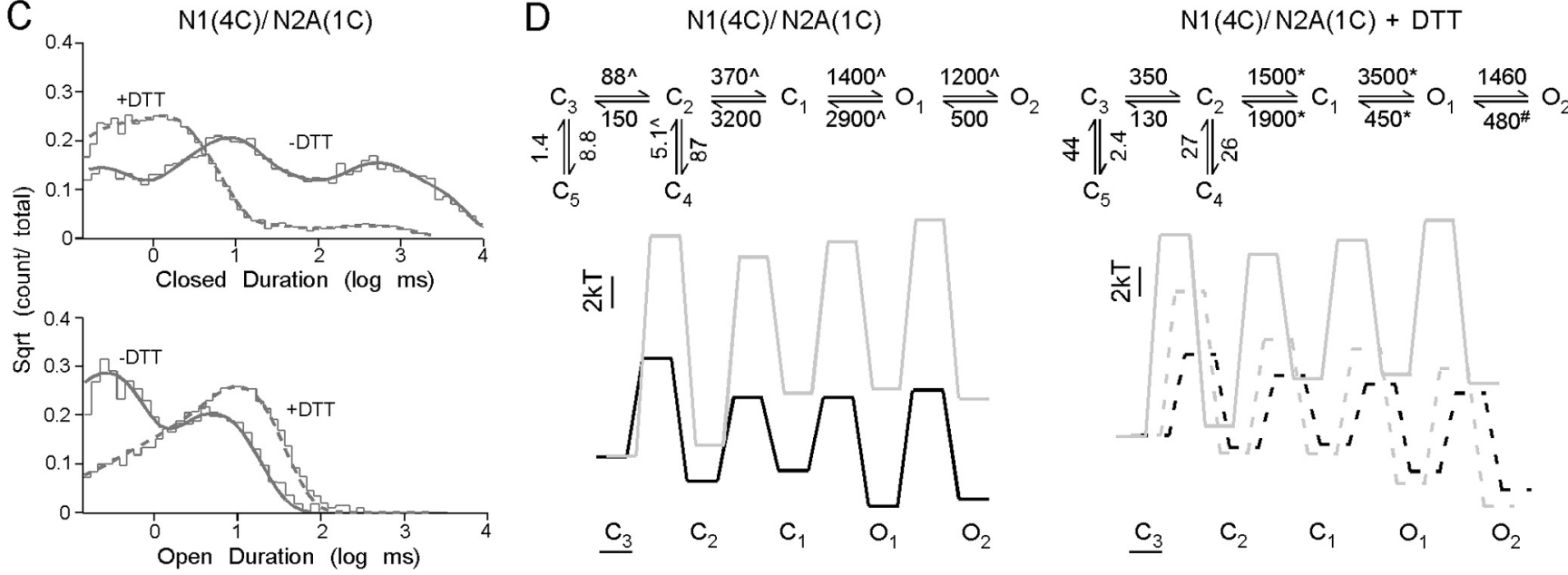

E
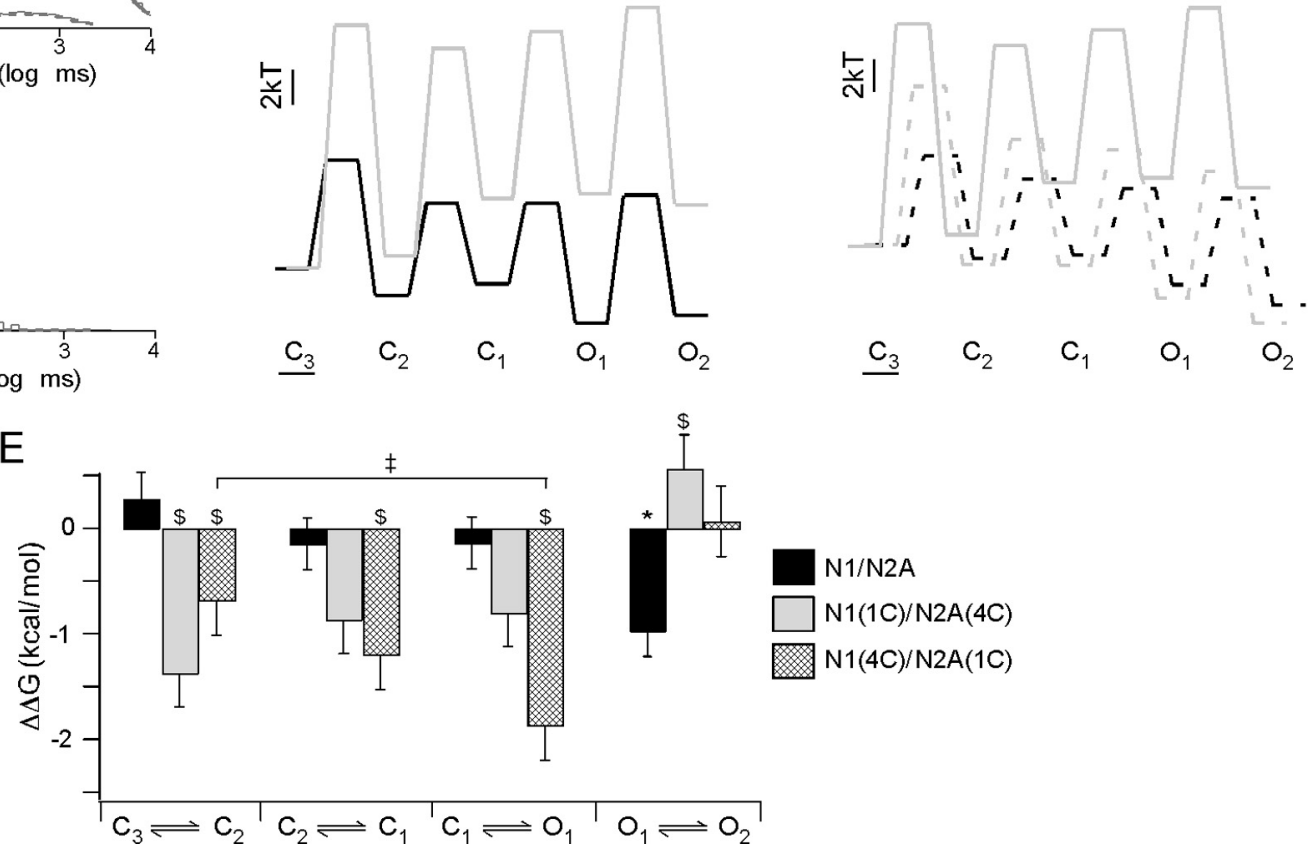

\section{$\mathrm{N} 1 / \mathrm{N} 2 \mathrm{~A}$ \\ $\mathrm{N} 1(1 \mathrm{C}) / \mathrm{N} 2 \mathrm{~A}(4 \mathrm{C})$ \\ $\mathrm{N} 1(4 \mathrm{C}) / \mathrm{N} 2 \mathrm{~A}(1 \mathrm{C})$}

Figure 8. Inter-subunit cross-linking of S1-M1 and S2-M4 disrupts early and late gating transitions. $A, C$, Closed- (top) and open- (bottom) time durations for GluN1(1C)/GluN2A(4C) (A) and GluN1(4C)/ GluN2A(1C) $(\boldsymbol{C})$ in the absence (solid gray lines) or presence (dashed gray lines) of DTT. Fits are as described in Figure 6A. B, D, Kinetic schemes (top) and energy landscapes (bottom) for GluN1 (1C)/GluN2A(4C) $(B)$ and GluN1(4C)/GluN2A(1C) (D) for the -DT (left column) and +DTT (right column) conditions. Results are displayed as in Figures $6 B$. For the left column, ${ }^{~}$ indicates rates significantly different from GluN1/GluN2A; for the right column, \# indicates rates significantly different from GluN1/GluN2A +DTT while *indicates rates significantly different from the respective $-D T T$ conditions $(p<0.05$, Student's t test). Number of patches: GluN1(1C)/GluN2A(4C),7(-DTT), 4(+DTT);GluN1(4C)/GluN2A(1C), 6(-DTT), 4(+DTT). B, D, Bottom, Energetic landscapes for tested constructs displayed as in Figure 7.E, Mean $\Delta \Delta G( \pm$ SEM) between the $+D T$ and $-D T$ conditions for GluN1/GluN2A, GluN1(1C)/GluN2A(4C), and GluN1(4C)/GluN2A(1C). Results are shown and analyzed as in Figure $7 E$.

equivalent within and between different subunits (Fig. 9A). Thus, our results demonstrate that elementary steps before pore opening in NMDA receptors occur in a stepwise and asynchronous manner.

\section{Constraining the mobility of the NMDA receptor} peripheral linkers

Based on structural homology to $\mathrm{K}^{+}$channels (Wo and Oswald, 1995; Sobolevsky et al., 2009) and functional studies (Jones et al.,
2002; Sobolevsky et al., 2002), pore opening in iGluRs is mediated by displacement of the pore-lining M3 helices away from the central axis of the pore (Traynelis et al., 2010). The peripheral transmembrane helices and their associated linkers closely surround these central gating elements and presumably must reposition to allow for pore opening (Sobolevsky et al., 2009). To study the dynamics of the peripheral elements during gating, we constrained the mobility of the peripheral linkers using pairs of introduced cysteines that spontaneously cross-linked (Figs. 2, 3, 

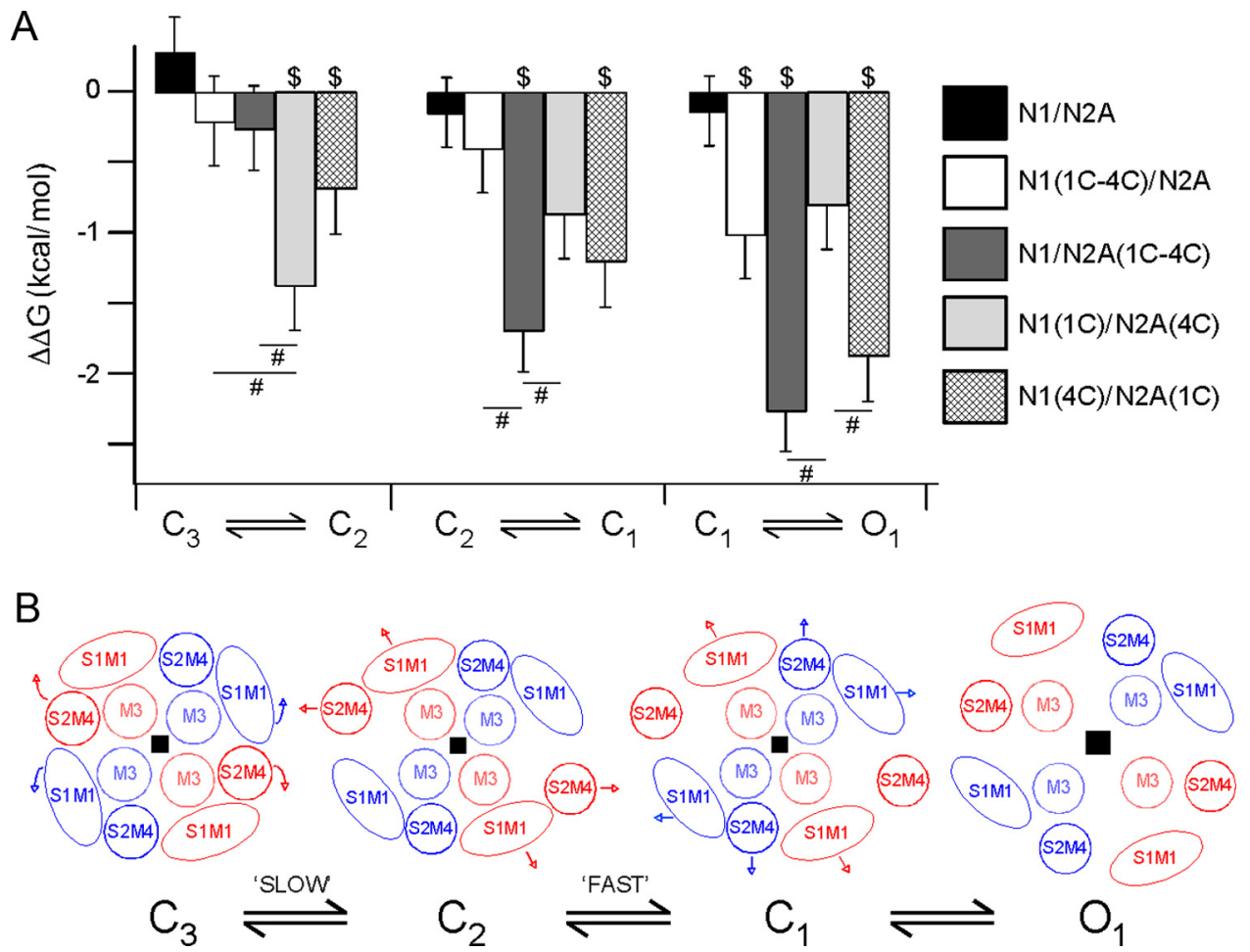

Figure 9. Thermodynamic progression of the peripheral linkers during NMDA receptor gating. $A, \Delta \Delta G$ plots for gating transitions $\left(C_{3}-C_{2}, C_{2}-C_{1}\right.$, and $\left.C_{1}-O_{1}\right)$ for wild-type and the four receptors with focal pairs of introduced cysteines. Values shown are from Figures $7 E$ and $8 E$. \# indicates significant differences between a specific transition for the indicated pair of constructs $(p<0.05$, Student's $t$ test). \$ indicates significant differences between a cysteine-substituted receptor and wild-type ( $p<0.05$, Student's $t$ test) for a specific transition. $\boldsymbol{B}$, Schematic of relative peripheral linker movements during NMDA receptor activation. GluN1 subunit is labeled in blue, GluN2A is in red. Relative subunit positioning incorporates previous structural and functional information (Sobolevsky et al., 2009; Salussolia et al., 2011a; Riou et al., 2012). Peripheral linkers and M3 are labeled accordingly. S1-M1 presumably occupies a larger volume due to its oblique orientation (Sobolevsky et al., 2009). Each model represents hypothesized positions for the specified state while arrows indicate the major peripheral linker rearrangements occurring as the channel approaches the $\mathrm{O}_{1}$ state. Arrow magnitudes are arbitrary and carry no physical meaning. Bottom, Linear activation scheme of NMDA receptors showing presumed slow and fast rearrangements.

4). We started with select positions in the linkers that had previously been shown to affect gating (Talukder et al., 2010). We then searched for potential proximal positions around each of the reference points using the GluA2 structure as a guide (Sobolevsky et al., 2009). We identified numerous pairs of proximal positions that spontaneously cross-linked (Figs. 2, 3, 4) and focused on four of them: two intra-subunit, GluN1(S531C-F792C) and GluN2A(V525C-D796C) [referredtoasGluN1(1C-4C)andGluN2A(1C-4C), respectively], and two inter-subunit, GluN1(F540C)/ GluN2A(S791C) and GluN1(P787C)/GluN2A(S535C) [referred to as GluN1(1C)/GluN2A(4C) and GluN1(4C)/GluN2A(1C), respectively]. We then performed single channel studies and thermodynamic analysis on these cysteine-substituted receptors as well as wild-type to address how constraining the peripheral linkers affected the dynamics of NMDA receptor gating. We assume that crosslinked receptors are not greatly distorted in their structure: the crosslinks were introduced in the peripheral linkers that are extended peptides and hence presumably have some degree of structural flexibility; the cross-linked receptors had gating properties (closed and open state distributions, single channel conductance) comparable to wild-type; and cross-links were able to reform in functional receptors (data not shown).

\section{Efficiency of NMDA receptor gating depends on the} conformational freedom of the peripheral linkers

Receptors containing introduced constraints of the peripheral linkers, either intra- or inter-subunit, showed dramatic reductions in single-channel $P_{\mathrm{o}}$ (Table 1 ). This effect was mainly due to the introduced constraints since all cysteine-substituted recep- tors showed a much greater DTT-induced potentiation in $P_{\mathrm{o}}$ than wild-type (Fig. 5, Table 1). These results directly support the idea that the peripheral linkers must undergo conformational rearrangements for efficient gating to occur (Balannik et al., 2005; Sobolevsky et al., 2009).

Although all constrained receptors showed a significantly reduced $P_{\mathrm{o}}$, the degree of this reduction was highly variable. Most notable is the distinction between the intra-GluN1 cross-links, which reduced $P_{\mathrm{o}}$ by only twofold, and intra-GluN2A cross-links, which reduced $P_{\mathrm{o}}$ by 62 -fold. The two intra-subunit constraints are positioned similarly between the $\mathrm{N}$-terminal end of the presumed pre-M1 helix and the N-terminal end of M4 (Fig. $2 A, B$, left). Therefore, the differing effects observed are unlikely to be due to drastic differences in the positioning of the constraints but rather due to different conformations adopted by the GluN1 and GluN2A subunits (Salussolia et al., 2011a; Riou et al., 2012).

\section{Elementary events before pore opening are asynchronous}

One of the hallmarks of the GluA2 structure was that the M1 and M4 helices and the associated S1-M1 and S2-M4 linkers were positioned around the central gating elements, the M3 helices and associated M3-S2 linkers (Sobolevsky et al., 2009). The displacements of these peripheral elements could be synchronized across all four subunits immediately following ligand binding, or could alternatively be out-of-phase with each other until shortly before pore opening. The analysis shown in Figure $9 A$ highlights that the different constraints between the peripheral linkers affect gating energetics at different points in the progression to pore opening, suggesting that their displacements are asynchronous. 
For example, the inter-subunit constraint between GluN1 S2-M4 and GluN2A S1-M1 [GluN1(4C)/GluN2A(1C)] significantly affects the energetics of all three major gating transitions while the constraint within GluN2A [GluN1/GluN2A(1C-4C)] only significantly affects the $\mathrm{C}_{2}-\mathrm{C}_{1}$ and $\mathrm{C}_{1}-\mathrm{O}_{1}$ transitions (Fig. 9A).

We incorporated these different energetic effects into a model describing the dynamics of the peripheral linkers during gating (Fig. $9 \mathrm{~B})$. During the early, "slow" gating transition $\left(\mathrm{C}_{3}-\mathrm{C}_{2}\right)$, major repositioning occurs between, rather than within, subunits particularly between GluN1 S1-M1 and GluN2A S2-M4. During the "fast" $\mathrm{C}_{2}-\mathrm{C}_{1}$ transition, however, a dramatic repositioning occurs within GluN2A. During the opening transition $\left(\mathrm{C}_{1}-\mathrm{O}_{1}\right)$, the predominant rearrangements occurred again among the GluN2A peripheral linkers, although the GluN1 S2-M4 and N2A S1-M1 linkers also repositioned relative to each other. Therefore, compared with the GluN1 subunits, the GluN2A subunits showed a greater degree of internal rearrangements at the linker level. This distinction is consistent with prior findings in AMPA receptors that subunits occupying the $\mathrm{B} / \mathrm{D}$ conformation (approximated by GluN2A in NMDA receptors) go through more extensive movements during gating relative to subunits in the A/C conformation (approximated by GluN1) (Dong and Zhou, 2011).

Without an open-state structure to define the endpoint of gating, specific structural changes occurring during gating cannot be absolutely defined. Further, our approach cannot delineate the direction and degree of the movements of each linker. Also, we are unable to specify which peripheral linker predominates during gating movements. Although we assume that the mobility of peripheral linkers primarily contributes to gating by allowing greater displacements of the central gating elements, they may also do so by effecting structural changes beyond M3 and M3-S2. Finally, for the kinetic modeling, we assumed that the slow and fast events occurred in an obligate order (Fig. 9B), but they may occur in a random order as exemplified by cyclic NMDA receptor gating models (Banke and Traynelis, 2003). Forcing events into a linear sequence might blur underlying kinetic rates. Still, given the robustness of effects on the slow and fast gating transitions (Fig. 9A), we assume that parallel effects would occur in the cyclic model (Erreger et al., 2005a). In such a scenario, the molecular rearrangements underlying the slow and fast transitions would still be asynchronous, although they would occur in any order.

\section{Implications to the mechanisms underlying NMDA receptor gating}

The peripheral linkers are positioned around the M3 helices and the M3-S2 linkers. Our results suggest that they undergo asynchronous rearrangements before pore opening. One possibility is that these asynchronous rearrangements converge on a subsequent preopen state that is permissive to the concerted movements of the M3 helices (Banke and Traynelis, 2003). Such a preopen converged state might be akin to the short-lived "flip" states observed in nicotinic and glycine receptors (Burzomato et al., 2004; Colquhoun and Lape, 2012). Alternatively, the displacements of the M3 helices may also occur asynchronously, with measurable currents only arising after all subunits have been displaced.

The mechanism of NMDA receptor partial agonism remains unknown. While altered LBD cleft closure contributes to partial activation in non- NMDA receptors (Hansen et al., 2007; Birdsey-Benson et al., 2010; Ahmed et al., 2011; Lau and Roux, 2011; Ramaswamy et al., 2012), this mechanism appears less sig- nificant to NMDA receptors as several partial agonists of the GluN1 subunit show near complete LBD cleft closure yet variable degrees of receptor activity (Inanobe et al., 2005; Kaye et al., 2006; Rambhadran et al., 2011; Ylilauri and Pentikäinen, 2012). Interestingly, partial agonists impede the kinetic mechanisms of NMDA receptor gating (Erreger et al., 2005b; Kussius and Popescu, 2009) but do not alter inherent single-channel properties. Moreover, the relative kinetic aberrations we report for GluN1(1C-4C)/GluN2A are remarkably comparable to the kinetics of GluN1/GluN2A receptor activation by GluN1 partial agonists (Kussius and Popescu, 2009). Hence, while partial agonists may induce full LBD cleft-closure, the events subsequent to binding may not permit complete peripheral linker rearrangements, similar to what we have presented, and thus dampen gating. Further elucidating how the dynamics of peripheral elements contribute to NMDA receptor partial agonism might lead to the development of novel pharmacological agents for potential clinical applications.

\section{References}

Ahmed AH, Wang S, Chuang HH, Oswald RE (2011) Mechanism of AMPA receptor activation by partial agonists: disulfide trapping of closed lobe conformations. J Biol Chem 286:35257-35266. CrossRef Medline

Armstrong N, Gouaux E (2000) Mechanisms for activation and antagonism of an AMPA-sensitive glutamate receptor: crystal structures of the GluR2 ligand binding core. Neuron 28:165-181. CrossRef Medline

Auerbach A, Zhou Y (2005) Gating reaction mechanisms for NMDA receptor channels. J Neurosci 25:7914-7923. CrossRef Medline

Balannik V, Menniti FS, Paternain AV, Lerma J, Stern-Bach Y (2005) Molecular mechanism of AMPA receptor noncompetitive antagonism. Neuron 48:279-288. CrossRef Medline

Banke TG, Traynelis SF (2003) Activation of NR1/NR2B NMDA receptors. Nat Neurosci 6:144-152. CrossRef Medline

Birdsey-Benson A, Gill A, Henderson LP, Madden DR (2010) Enhanced efficacy without further cleft closure: reevaluating twist as a source of agonist efficacy in AMPA receptors. J Neurosci 30:1463-1470. CrossRef Medline

Borschel WF, Murthy SE, Kasperek EM, Popescu GK (2011) NMDA receptor activation requires remodelling of intersubunit contacts within ligand-binding heterodimers. Nat Commun 2:498. CrossRef Medline

Burzomato V, Beato M, Groot-Kormelink PJ, Colquhoun D, Sivilotti LG (2004) Single-channel behavior of heteromeric alphalbeta glycine receptors: an attempt to detect a conformational change before the channel opens. J Neurosci 24:10924-10940. CrossRef Medline

Chang HR, Kuo CC (2008) The activation gate and gating mechanism of the NMDA receptor. J Neurosci 28:1546-1556. CrossRef Medline

Colquhoun D, Hawkes AG (1990) Stochastic properties of ion channel openings and bursts in a membrane patch that contains two channels: evidence concerning the number of channels present when a record containing only single openings is observed. Proc R Soc Lond B Biol Sci 240:453-477. CrossRef Medline

Colquhoun D, Lape R (2012) Perspectives on: Conformational coupling in ion channels: allosteric coupling in ligand-gated ion channels. J Gen Physiol 140:599-612. CrossRef Medline

Dingledine R, Borges K, Bowie D, Traynelis SF (1999) The glutamate receptor ion channels. Pharmacol Rev 51:7-61. Medline

Dong H, Zhou HX (2011) Atomistic mechanism for the activation and desensitization of an AMPA-subtype glutamate receptor. Nat Commun 2:354. CrossRef Medline

Dravid SM, Prakash A, Traynelis SF (2008) Activation of recombinant NR1/ NR2C NMDA receptors. J Physiol 586:4425-4439. CrossRef Medline

Erreger K, Traynelis SF (2008) Zinc inhibition of rat NR1/NR2A N-methylD-aspartate receptors. J Physiol 586:763-778. Medline

Erreger K, Dravid SM, Banke TG, Wyllie DJ, Traynelis SF (2005a) Subunitspecific gating controls rat NR1/NR2A and NR1/NR2B NMDA channel kinetics and synaptic signalling profiles. J Physiol 563:345-358. Medline

Erreger K, Geballe MT, Dravid SM, Snyder JP, Wyllie DJ, Traynelis SF (2005b) Mechanism of partial agonism at NMDA receptors for a conformationally restricted glutamate analog. J Neurosci 25:7858-7866. CrossRef Medline 
Furukawa H, Singh SK, Mancusso R, Gouaux E (2005) Subunit arrangement and function in NMDA receptors. Nature 438:185-192. CrossRef Medline

Hansen KB, Yuan H, Traynelis SF (2007) Structural aspects of AMPA receptor activation, desensitization and deactivation. Curr Opin Neurobiol 17:281-288. CrossRef Medline

Inanobe A, Furukawa H, Gouaux E (2005) Mechanism of partial agonist action at the NR1 subunit of NMDA receptors. Neuron 47:71-84. CrossRef Medline

Jones KS, VanDongen HM, VanDongen AM (2002) The NMDA receptor M3 segment is a conserved transduction element coupling ligand binding to channel opening. J Neurosci 22:2044-2053. Medline

Kaye SL, Sansom MS, Biggin PC (2006) Molecular dynamics simulations of the ligand-binding domain of an $N$-methyl-D-aspartate receptor. J Biol Chem 281:12736-12742. CrossRef Medline

Kleckner NW, Dingledine R (1988) Requirement for glycine in activation of NMDA-receptors expressed in Xenopus oocytes. Science 241:835-837. CrossRef Medline

Krupp JJ, Vissel B, Heinemann SF, Westbrook GL (1998) N-terminal domains in the NR2 subunit control desensitization of NMDA receptors. Neuron 20:317-327. CrossRef Medline

Kussius CL, Popescu GK (2009) Kinetic basis of partial agonism at NMDA receptors. Nat Neurosci 12:1114-1120. CrossRef Medline

Kussius CL, Popescu AM, Popescu GK (2010) Agonist-specific gating of NMDA receptors. Channels 4:78-82. CrossRef Medline

Lau AY, Roux B (2011) The hidden energetics of ligand binding and activation in a glutamate receptor. Nat Struct Mol Biol 18:283-287. CrossRef Medline

Long SB, Campbell EB, Mackinnon R (2005) Crystal structure of a mammalian voltage-dependent Shaker family $\mathrm{K}+$ channel. Science 309: 897-903. CrossRef Medline

Mayer ML (2006) Glutamate receptors at atomic resolution. Nature 440: 456-462. CrossRef Medline

Popescu G, Auerbach A (2003) Modal gating of NMDA receptors and the shape of their synaptic response. Nat Neurosci 6:476-483. Medline

Ramaswamy S, Cooper D, Poddar N, MacLean DM, Rambhadran A, Taylor JN, Uhm H, Landes CF, Jayaraman V (2012) Role of conformational dynamics in alpha-amino-3-hydroxy-5-methylisoxazole-4-propionic acid (AMPA) receptor partial agonism. J Biol Chem 287:43557-43564. CrossRef Medline

Rambhadran A, Gonzalez J, Jayaraman V (2011) Conformational changes at the agonist binding domain of the $\mathrm{N}$-methyl-D-aspartic acid receptor. J Biol Chem 286:16953-16957. CrossRef Medline

Regalado MP, Villarroel A, Lerma J (2001) Intersubunit cooperativity in the NMDA receptor. Neuron 32:1085-1096. CrossRef Medline

Ren H, Zhao Y, Dwyer DS, Peoples RW (2012) Interactions among positions in the third and fourth membrane-associated domains at the intersubunit interface of the $\mathrm{N}$-methyl-D-aspartate receptor forming sites of alcohol action. J Biol Chem 287:27302-27312. CrossRef Medline

Riou M, Stroebel D, Edwardson JM, Paoletti P (2012) An alternating GluN1-2-1-2 subunit arrangement in mature NMDA receptors. PLoS One 7:e35134. CrossRef Medline
Rosenmund C, Stern-Bach Y, Stevens CF (1998) The tetrameric structure of a glutamate receptor channel. Science 280:1596-1599. CrossRef Medline

Salussolia CL, Prodromou ML, Borker P, Wollmuth LP (2011a) Arrangement of subunits in functional NMDA receptors. J Neurosci 31:11295-11304. CrossRef Medline

Salussolia CL, Corrales A, Talukder I, Kazi R, Akgul G, Bowen M, Wollmuth LP (2011b) Interaction of the M4 segment with other transmembrane segments is required for surface expression of mammalian alpha-amino3-hydroxy-5-methyl-4-isoxazolepropionic acid (AMPA) receptors. J Biol Chem 286:40205-40218. CrossRef Medline

Schmid SM, Körber C, Herrmann S, Werner M, Hollmann M (2007) A domain linking the AMPA receptor agonist binding site to the ion pore controls gating and causes lurcher properties when mutated. J Neurosci 27:12230-12241. CrossRef Medline

Schorge S, Elenes S, Colquhoun D (2005) Maximum likelihood fitting of single channel NMDA activity with a mechanism composed of independent dimers of subunits. J Physiol 569:395-418. CrossRef Medline

Smith TC, Howe JR (2000) Concentration-dependent substate behavior of native AMPA receptors. Nat Neurosci 3:992-997. CrossRef Medline

Sobolevsky AI, Beck C, Wollmuth LP (2002) Molecular rearrangements of the extracellular vestibule in NMDAR channels during gating. Neuron 33:75-85. CrossRef Medline

Sobolevsky AI, Rosconi MP, Gouaux E (2009) X-ray structure, symmetry and mechanism of an AMPA-subtype glutamate receptor. Nature 462: 745-756. CrossRef Medline

Sun Y, Olson R, Horning M, Armstrong N, Mayer M, Gouaux E (2002) Mechanism of glutamate receptor desensitization. Nature 417:245-253. CrossRef Medline

Talukder I, Wollmuth LP (2011) Local constraints in either the GluN1 or GluN2 subunit equally impair NMDA receptor pore opening. J Gen Physiol 138:179-194. CrossRef Medline

Talukder I, Borker P, Wollmuth LP (2010) Specific sites within the ligandbinding domain and ion channel linkers modulate NMDA receptor gating. J Neurosci 30:11792-11804. CrossRef Medline

Talukder I, Kazi R, Wollmuth LP (2011) GluN1-specific redox effects on the kinetic mechanism of NMDA receptor activation. Biophys J 101: 2389-2398. CrossRef Medline

Traynelis SF, Wollmuth LP, McBain CJ, Menniti FS, Vance KM, Ogden KK, Hansen KB, Yuan H, Myers SJ, Dingledine R (2010) Glutamate receptor ion channels: structure, regulation, and function. Pharmacol Rev 62:405496. CrossRef Medline

Wo ZG, Oswald RE (1995) Unraveling the modular design of glutamategated ion channels. Trends Neurosci 18:161-168. CrossRef Medline

Wyllie DJ, Béhé P, Colquhoun D (1998) Single-channel activations and concentration jumps: comparison of recombinant NR1a/NR2A and NR1a/NR2D NMDA receptors. J Physiol 510:1-18. CrossRef Medline

Yelshansky MV, Sobolevsky AI, Jatzke C, Wollmuth LP (2004) Block of AMPA receptor desensitization by a point mutation outside the ligandbinding domain. J Neurosci 24:4728-4736. CrossRef Medline

Ylilauri M, Pentikäinen OT (2012) Structural mechanism of N-methyl-Daspartate receptor type 1 partial agonism. PLoS One 7:e47604. CrossRef Medline 